Article

\title{
Internal Heat Gains in a Lunar Base-A Contemporary Case Study
}

\author{
Marcin Kaczmarzyk ${ }^{1, *(\mathbb{D})}$, Aleksander Starakiewicz ${ }^{1}$ and Aleksander Waśniowski ${ }^{2}$ (D) \\ 1 Faculty of Civil and Environmental Engineering and Architecture, Rzeszow University of Technology, \\ ul. Poznanska 2, 35-959 Rzeszow, Poland; olekstar@prz.edu.pl \\ 2 LUNARES Mobile Research Station, Space Garden ltd., Pl. Wolnosci 13/2, 35-073 Rzeszow, Poland; \\ aleksander.wasniowski@gmail.com \\ * Correspondence: kaczmar@prz.edu.pl; Tel.: +48-17-8651026
}

Received: 3 May 2020; Accepted: 16 June 2020; Published: 20 June 2020

Abstract: The Moon's environmental conditions present limited opportunities for waste heat dissipation, so internal heat gains (IHG) are a key component of thermal balance in a lunar building. Despite the significant development in energy saving and energy storage technologies of the last thirty years, the issue of IHG in lunar buildings has not been readdressed since the early 1990s. This study is based on an inspection of internal heat sources conducted aboard LUNARES, the first European extraterrestrial analogue habitat. The equipment absent on LUNARES, but indispensable for an actual lunar base, was identified and accounted for, along with additional laboratory and maintenance equipment. Three main groups of internal heat sources were identified and studied in detail. Waste heat generated by electric devices was accounted for, along with occupational heat loads adjusted for lunar partial gravity conditions. Assuming a photovoltaic power source for the studied building, two alternative energy storage systems (ESS) were analysed as another source of waste heat. Depending on the time of lunar day and applied ESS, the nominal IHG were between 73 and $133 \mathrm{~W} / \mathrm{m}^{2}$. The most significant internal heat sources in a lunar base are life support systems and potentially, regenerative fuel cells; thus, lithium-ion batteries were recommended for ESS. Within assumed parameter range, parametric study exhibited differences in IHG between 41.5 and $163 \mathrm{~W} / \mathrm{m}^{2}$.

Keywords: extraterrestrial building physics; internal heat gain; energy storage; occupational heat load; analogue planetary base

\section{Introduction}

\subsection{Analogue Planetary Bases}

The development of manned space exploration requires the ability to test new technologies and human behaviour in safe and controlled conditions, before an actual spaceflight takes place. Analogue planetary bases, also known as analogue extraterrestrial bases or habitats, are specially designed facilities where selected aspects of long term human presence on extraterrestrial bodies may be simulated. In these facilities, technological solutions, procedures and guidelines for future Moon and Mars exploration are studied and improved. Already, there are several analogue planetary bases in the world, and new ones are being developed [1-4].

\subsection{LUNARES}

The first analogue extraterrestrial habitat in Europe is LUNARES, located at a former military airport in Piła, Poland. The name "LUNARES" is a combination of the words Luna (the Moon) and Ares (Mars), because of the fact that it is intended to simulate both lunar and Martian missions. 
The habitat became operational in July 2017, beginning a fourteen-day-long analogue Mars mission for a six-personnel international crew. LUNARES consists of a spacious central domed hub called Atrium and eight adjacent modules, listed in Table 1.

Table 1. Compartments in LUNARES habitat.

\begin{tabular}{cccc}
\hline No. & Compartment & Floor Surface Area $\left[\mathbf{m}^{2}\right]$ & Interior Volume $\left[\mathbf{m}^{3}\right]$ \\
\hline 1 & Workshop & 17.2 & 28.8 \\
2 & Storage & 13.0 & 34.4 \\
3 & Galley & 13.0 & 30.4 \\
4 & Dormitory & 19.7 & 49.2 \\
5 & Operations room & 19.7 & 49.2 \\
6 & Biolab & 8.0 & 18.3 \\
7 & Bathroom & 8.0 & 18.3 \\
8 & Atrium & 37.2 & 150.0 \\
9 & Airlock & 15.5 & 34.0 \\
& total: & 151.3 & 412.6 \\
& regulated temperature: & 135.8 & 378.6 \\
\hline
\end{tabular}

The layout of the LUNARES habitat is presented in Figure 1. Numeration of the compartments is the same as in Table 1.

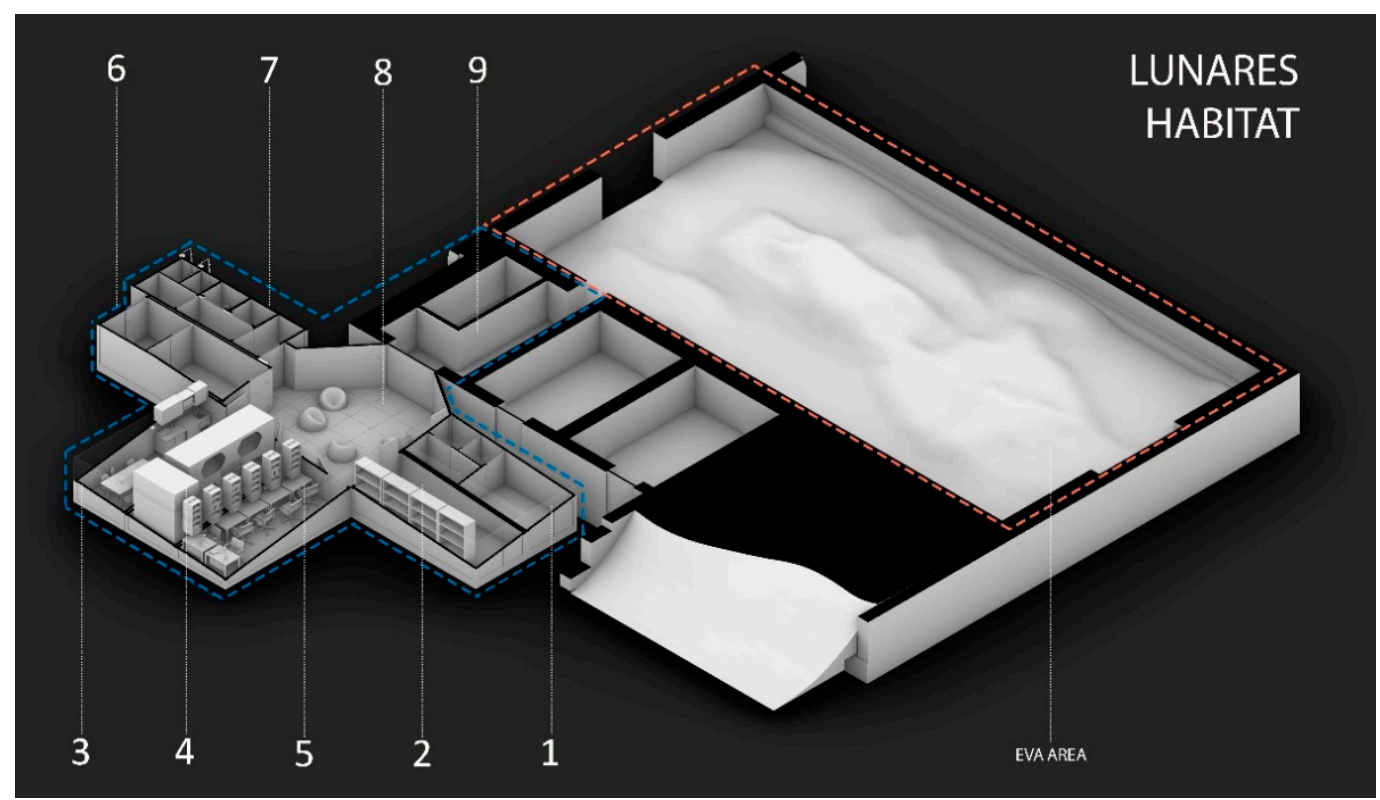

Figure 1. An axonometric projection of the LUNARES habitat three-dimensional (3D) model. Source: Leszek Orzechowski and Agata Mintus.

The secondary component of the LUNARES complex is a simulated lunar and Martian terrain, situated inside a reinforced aircraft hangar.

Figure 2 presents the LUNARES habitat and its vicinity. The hangar containing extravehicular activities (EVA) area is covered with undergrowth. 


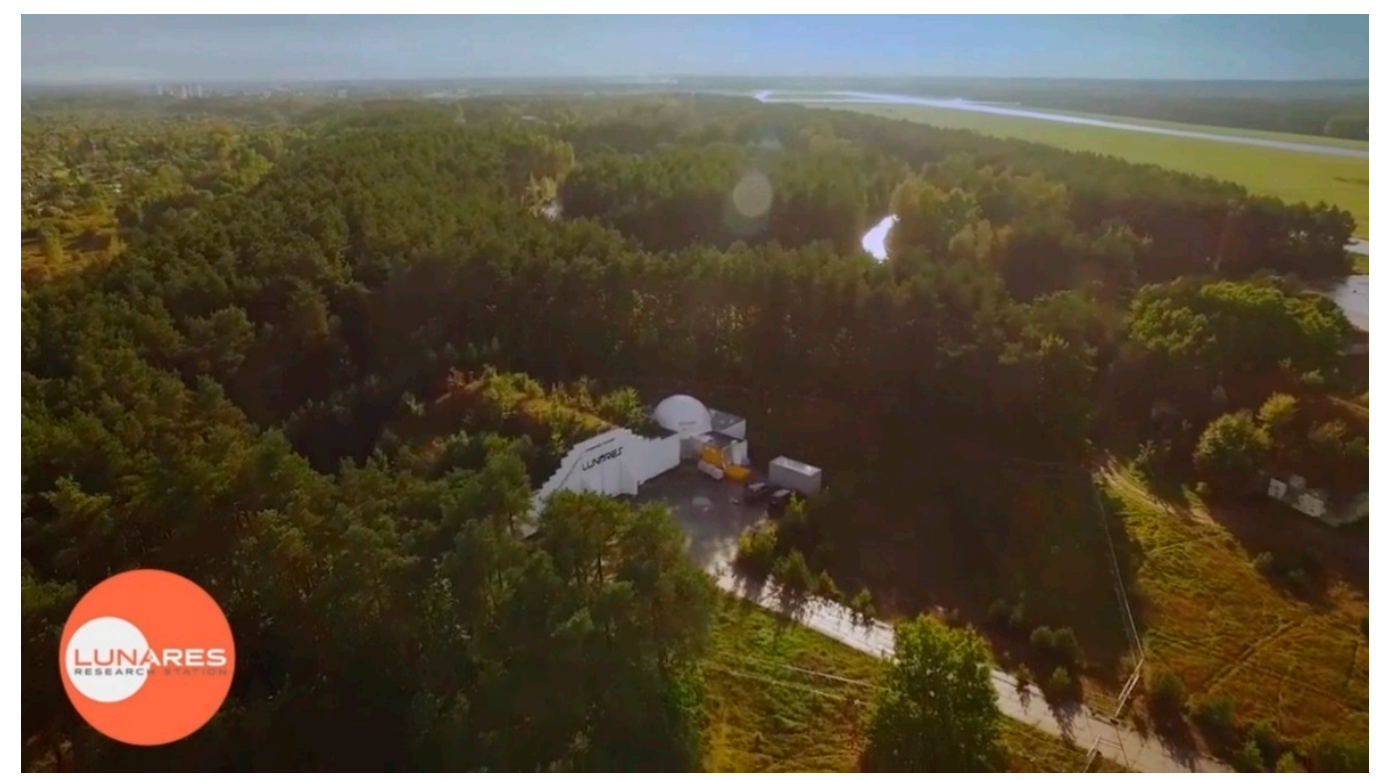

Figure 2. LUNARES and its vicinity. Source: Space is More.

The whole facility has been made completely lightproof to enable studies on human circadian rhythm and plant growth with artificial lighting.

\subsection{Internal Heat Gains}

In building physics, internal heat gains (IHG) or internal heat loads refer to heat emitted by all physical phenomena, activities and processes that release sensible and latent heat inside a building envelope, but are not a part of the building's heating system [5-7]. The most important internal heat sources are occupants' body heat, electric devices, food preparation and domestic water heating. As a byproduct of the abovementioned phenomena, IHG cannot be controlled without disrupting the functioning of a building. Internal heat gains increase the building's interior temperature and may considerably contribute to the building's thermal balance, especially in well thermally insulated objects $[5,8]$. The importance of IHG for thermal and energy performance of buildings were also addressed in [9-12]. In the subject literature, the terms "heat gains" and "heat loads" are often used interchangeably [7]. In this paper we use the term "heat loads" for particular internal heat fluxes of a specified origin; whereas "internal heat gains" refer to the whole class of these heat loads or their total value.

\subsection{Internal Heat Gains in Extraterrestrial Buildings}

The settlements to be established on the surface of the Moon or Mars will initially serve as scientific facilities, so it may be expected, that they will be equipped with a great variety of electrically powered devices. Additional heat will be produced by batteries and life support systems, such as water recovery and atmospheric control systems [13]. Moreover, due to the extremely high costs of space transportation, these early extraterrestrial buildings would have highly limited volume and floor surface areas. These two factors suggest, that internal heat loads per unit of floor surface in these buildings may be significantly higher than what we observe in residential or office buildings on Earth. Due to a lack of atmosphere (the Moon) or very low atmospheric pressure (Mars), both locations may be considered as highly insulative environments, where heat exchange between the building's interior and exterior is highly limited [13-19]. In terrestrial conditions typical $25 \frac{\mathrm{W}}{\mathrm{m}^{2} \mathrm{~K}}$ external surface heat transfer coefficient is assumed, including $\sim 5 \frac{\mathrm{W}}{\mathrm{m}^{2} \mathrm{~K}}$ for its radiative component [20-22]. At the lunar surface the convective heat transfer is absent, but the lunar night-time heat losses may be as high as $15 \frac{\mathrm{W}}{\mathrm{m}^{2}}$ [14]. This is mostly due to lack of the atmosphere and the greenhouse effect. On the Moon, exposed surfaces 
radiates heat directly into the outer space of effective temperature $\sim 3 \mathrm{~K}$. In that situation, determination of internal heat gains becomes a matter of great importance to the design of an adequate thermal control system (TCS). Space-rated TCS are systems of considerable mass, so their performance optimization influences the cost of the base transportation [23]. Moreover, the TCS is one of the crucial elements of any extraterrestrial building, as it enables human habitation in a hostile space environment [13]. Extensive research on this subject was conducted in the 1980s and the early-1990s, based on technologies and space exploration strategies of that time. In their study on a lunar base thermal control system, Simonsen et al.1988 [14] considered orbital space station heat load requirements specified by National Aeronautics and Space Administration (NASA) in 1984. The calculated total internal heat load for the subterranean lunar base was about $200 \mathrm{~kW}$. Based on more mature technologies, Swanson et al. 1990 [15] attempted to revisit the assumptions made by Simonsen et al.1988 [14]. They calculated that the former heat load values were overestimated by about $50 \%$ with respect to their results. In 1992, Simonsen et al. revised their initial assumptions, obtaining the new load estimate to be $135 \mathrm{~kW} \mathrm{[16].}$ This approach provided a total internal heat load of a subterranean laboratory and habitation modules as high as $250 \mathrm{~W} / \mathrm{m}^{2}$. In order to determine the cooling load for a heat pump-based temperature control system (TCS), Sridhar et al. 1996 [17] assumed the total heat load of a studied lunar base to be $100 \mathrm{~kW}$. It is however, important to notice that all mentioned studies either did not address the issue of energy storage systems (ESS) or assumed nuclear power sources for their lunar facilities. Present strategies for the early stages of manned lunar exploration promote solar-based energy solutions [18,24,25], that require application of energy storage systems. Landis and Bailey [26] presented their estimation of the minimal electric power demand of an initial, solar powered lunar settlement with a biological air revitalization system to be $25 \mathrm{~kW}$. The most recent works $[24,25,27]$ recognise the importance of the IHG issue in lunar settlements, but does not address it in detail. Numerous works $[15-17,26]$ point out the necessity for a more custom approach to lunar bases heat gains, to be done by addressing their individual architectures, contemporary technologies and mission profiles. This cannot be accomplished just by analysing preliminary concepts, but by studying serious projects and fully equipped analogue lunar bases with ongoing experiments. Such opportunity presented itself during the Innovative Concepts Ares-1 (ICAres-1) analogue mission aboard the LUNARES habitat, where numerous scientific experiments were being performed. There were, among others: in situ material processing and utilisation, plant cultivation and animal breeding, three-dimensional (3D) printing of spare parts, electromagnetic radiation measurements, group dynamics monitoring, continuous artificial lighting studies, and extravehicular equipment testing. Although LUNARES lacked working life support systems, it was well-equipped with laboratory and everyday-life devices, so studying its internal heat sources offered reliable insight into future, full scale solutions. The purpose of this study was to re-evaluate the internal heat gains in future lunar buildings, by applying state-of-the-art equipment parameters to an existing structure, specially designed for the simulations of space planetary activities.

\section{Materials and Methods}

\subsection{Assumptions}

It was assumed, that the studied base is located at low latitudinal regions of the Moon and the entire complex is situated on the lunar surface, without any subterranean sections. The overall shape and compartments layout of the LUNARES habitat were adapted here, although we assumed the envelope to be completely opaque, airtight and covered with multilayer insulation to minimise radiative heat exchange with outer space. We assumed the studied lunar base crew biometrics to be the same as the ICAres- 1 crew's. Issues of cosmic radiation protection were not considered in this paper. The term LUNARES always refers here to the actual, existing analogue base building whereas "the lunar base" or just "the base" refers to the subject of this paper, i.e., to an assumed building located at the Moon's surface of the same architecture as LUNARES. Wherever "day" or "daily" are used in 
this article, they refer to earth days $(24 \mathrm{~h})$. When referring to the lunar diurnal cycle, we always specify it as lunar day (LD) or lunar night (LN).

\subsection{Method}

The purpose of this paper was to assess the total value of internal heat gains of a future lunar base of the same architecture and function assimilated in the LUNARES habitat during the ICAres-1 mission. It was accomplished by revisiting the actual inventory of LUNARES [28], adjusting and supplementing it to mirror a complete inventory of a lunar scientific facility according to contemporary baselines for space station subsystems $[13,24,25]$. State-of-the-art electric devices were assumed to be used aboard the base. The profiles of physical activities of the crew were also elaborated and adjusted to long-term lunar mission demands.

Assessment of internal heat gains performed aboard LUNARES [28] was based on:

- thorough inspection of all electric devices inside the station, i.e., learning their input power and daily use;

- $\quad$ surveying the crew members on their biometrics, physical activities, electric devices they used during the mission, and information about a lack of equipment for their personal or scientific needs.

The inspection and the survey were performed in October 2017, during the ICAres-1 analogue mission. All subjects gave their informed consent for inclusion before they participated in the study. The study was conducted in accordance with the Declaration of Helsinki, and the protocol was approved by the Ethics Committee of Karol Marcinkowski Medical University in Poznan on 06.07.2017 (project identification code 685/17). The corresponding author of this paper was one of the ICAres-1 crew members and spent two weeks aboard the station, acting as a Structural material specialist and a PR officer. Thanks to this, the authors possessed first-hand information about the station's inventory use and actual, everyday mission schedules. The crew of ICAres- 1 included a physicist, medical doctor, IT specialist, technician, and two engineers. Four of the crew were specialists in selected aspects of space engineering. For the purpose of this paper, information was gathered from crew members by specially prepared questionnaires, which addressed the following issues:

- their mission assignments, sex, body weight and height;

- daily profile of their physical activities;

- electric devices brought for their personal use or research purposes;

- personal use electric devices, laboratory equipment, subsystems, or installations that LUNARES lacks for long-term lunar mission.

We divided internal heat sources of the lunar base into three separate categories:

- electric devices (existing base equipment, crew's personal devices and supplementary equipment, including life support);

- occupational heat sources (sensible body heat and occupational latent heat);

- energy storage system.

\subsection{Heat Loads from Electric Devices}

It was assumed, that all electric energy expended inside the base will eventually be transformed into heat, allowing it to be counted totally as internal heat loads. It will be the case even with domestic hot water, which will cycle in a sustainable closed loop. Based on the definition of power and knowing the value of nominal power input and daily use of selected electric devices one may calculate their contribution to the mean internal heat load:

Equation (1). Heat load from electric devices.

$$
Q_{E D}=\sum_{i} \frac{P_{i} \times t_{\text {mean. } i}}{24}[\mathrm{~W}]
$$


where: $Q_{E D}$ is the daily mean power demand of a group of electric devices, i.e., its contribution to daily mean internal heat load, $P_{i}$ is the mean power input of $i$ device [W], $t_{\text {mean }, i}$ is the mean time of $i$ device daily use [h] and 24 is the number of hours per day. Heat loads from base equipment, personal devices, life support and from supplementary devices were calculated according to Equation (1). Electric devices used only outside the habitat during extravehicular activities (EVA) but recharged indoors, were accounted for according to Equation (2), based on the definition of power and energy efficiency: Equation (2). Heat load from portable equipment battery charging:

$$
Q_{C h}=\frac{P_{C h} \times t_{C h} \times\left(1-\eta_{C h}\right)}{24}[\mathrm{~W}]
$$

where $P_{C h}$ is the nominal power of the battery charger, $t_{C h}$ is the daily mean time of charging and $\eta_{C h}$ is the energy efficiency of battery charging.

Calculation of heat load from base equipment $\mathrm{Q}_{\mathrm{BE}}$ was based on the modified inventory available aboard the LUNARES habitat [28]. The modifications consider replacing all the fluorescent lamps with Light-Emitting Diodes (LEDs), and removing the air dryer, fans and all the network hardware. Interior air circulation and humidity control subsystems were considered as parts of the life support system, accounted for in the further part of this paper (Table 7). Any network hardware was considered as parts of the communication system, also included in Table 7. The EVA battery charger was removed from the list assuming the communication was included in the spacesuit power system (Table 7). The ultraviolet decontamination lamp from the original inventory was found to be expendable in the lunar environment. The total power demand of the group dynamics experiment Social Sensing System (SocSenSys) was established using the experiment description [29,30]. Domestic water heating parameters were also changed. We increased daily domestic hot water consumption up to $15 \mathrm{~L} /$ man-day and water temperature difference was assumed to be $25 \mathrm{~K}$ (from ambient $23^{\circ} \mathrm{C}$ to $48{ }^{\circ} \mathrm{C}$ ) with total efficiency of the system equalling $85 \%$. The inventory of the crew's personal devices remain the same as presented in [28]. A list of supplementary devices was created as a synthesis of actual guidelines for space and planetary stations design $[13,24,25]$ and the survey conducted among the ICAres- 1 crew, where the crew members have suggested additions to the base inventory, necessary for their research and comfort. As a life support system, we considered atmospheric control and water recovery subsystems similar to those actually used aboard the International Space Station (ISS) [31]. As a communication system we assumed a two-way optical communication with Earth [32] and all internal network hardware. For safety reasons, it is a common practice in astronautics to double or to triple the essential systems or components of spacecrafts. It is indispensable for a lunar base to have such redundant systems as well. For the purpose of this analysis we assumed, that as long as the primary systems are operational, their backups remain in standby mode and require negligible amounts of energy.

\subsection{Occupational Heat Loads}

\subsubsection{Sensible Body Heat}

Calculation of sensible body heat emitted to the surroundings by a person is based on their body surface area and on their instantaneous metabolic rate. The latter is expressed in Metabolic Equivalent of Task (MET) units, which represents a ratio of the rate at which a person expends energy, while performing a given physical activity compared to a reference value, equivalent to the energy expended when sitting idly (in terrestrial conditions). By definition, the reference value $\mathrm{MET}_{0}=58.2 \mathrm{~W} / \mathrm{m}^{2}$ [33]. The total body surface areas (BSA) for the crew members were calculated using the Du Bois formula:

Equation (3). DuBois formula for calculating body surface area [34].

$$
B S A=0.007184 \times m^{0.425} \times h^{0.725}\left[\mathrm{~m}^{2}\right]
$$


where: $B S A$ is body surface area $\left[\mathrm{m}^{2}\right], m$ is body mass $[\mathrm{kg}]$ and $h$ is the person's height $[\mathrm{cm}]$.

Table 2 presents the results of ICAres- 1 crew BSA calculations.

Table 2. Body surface areas of the Innovative Concepts Ares-1 (ICAres-1) crew.

\begin{tabular}{cc}
\hline Crew Member & Body Surface Area $\left[\mathbf{m}^{2}\right]$ \\
\hline A & 1.65 \\
B & 1.63 \\
C & 1.89 \\
D & 1.86 \\
E & 1.88 \\
F & 2.25 \\
\hline
\end{tabular}

The largest uncertainty factor for determining metabolic heat loads in lunar intravehicular conditions are MET values for physical activities under partial lunar gravity. Thanks to almost two decades of extensive studies on human physiology conducted aboard the International Space Station (ISS), metabolic rates MET for zero-g are well known [13]. Unfortunately, this is not the case for lunar, one-sixth Earth's gravity (g). Throughout the last five decades, numerous studies on this subject have been performed in various partial gravity simulators [35-40]. The data collected during Apollo lunar EVAs allowed for limited estimations of metabolic rates and only for a relatively narrow range of physical activities, performed mostly in pressurized spacesuits. The results of all these studies are inconclusive and have more of a rather qualitative than quantitative character [41]. We decided to address the subject based on recent lunar ambulation studies performed by NASA [40]. Based on the data collected in the survey, the mission profile of ICAres- 1 and its daily schedules, the daily physical activities of the crew were divided into three categories. The division and respective values of terrestrial vs. lunar metabolic rates assumed for our calculations are presented in Table 3.

Table 3. Metabolic rates assumed for intravehicular activities at the lunar surface.

\begin{tabular}{ccccc}
\hline $\begin{array}{c}\text { Activity } \\
\text { Symbol }\end{array}$ & Activity Description & $\begin{array}{c}\text { Terrestrial MET } \\
\text { Range }\end{array}$ & $\begin{array}{c}\text { Average } \\
\text { Terrestrial MET }\end{array}$ & $\begin{array}{c}\text { Average Lunar } \\
\text { MET }\end{array}$ \\
\hline PA-1 & sleep and relaxation & $0.8-1.0$ & 0.9 & 0.9 \\
PA-2 & Light, mostly sedentary activities & $1.6-2.2$ & 1.9 & 1.66 \\
PA-3 & exercises and moderate intensity activities & $4.0-6.0$ & 5 & 2.5 \\
\hline
\end{tabular}

MET, Metabolic Equivalent of Task; PA, Physical Activity.

The daily physical activities timetable assumed for our calculations is based mostly on the ICAres-1 actual timetable [28], however some refinements were made. First of all, Physical Activity-1 (PA-1) time has been extended up to nine hours because of the necessity for maintaining an eight $h /$ day sleep duration. Secondly, the timetable was split into 'lunar day' and 'lunar night' versions. It was assumed, that EVAs take place only during lunar days, a typical EVA is conducted once every three days and involves three astronauts for $4.5 \mathrm{~h}$, which gives an average $0.75 \mathrm{~h}$ EVA time per man-day. In order to attenuate the physical deconditioning effects of living in partial gravity, astronauts will be required to spend adequate time performing specially-designed exercises [41]. This issue was addressed by increasing the minimal time spent on PA-3 up to $2 \mathrm{~h} /$ day during lunar nights. To some extent, individual preferences for physical activities were also considered here, along with the specificity of the position of each individual. Considering EVAs as moderate and vigorous physical activities, PA-3 durations on lunar days were reduced by $0.75 \mathrm{~h} / \mathrm{man}$-day. We assumed a constant, $23^{\circ} \mathrm{C}$ ambient temperature inside the base. As a result of proper adjustments to clothing for specified physical activity, it is possible to assume, that the base crew members will function in thermoneutral conditions, i.e., they will not expend extra energy to maintain their body temperature. Temporary increases in metabolic heat production that may last some time after the astronauts return from EVAs were judged to be negligible 
for the overall internal heat gain and were not addressed in the calculations. The daily mean heat load from the crew's sensible body heat was calculated as:

Equation (4). Daily mean sensible body heat load.

$$
Q_{S B H}=\sum_{i, j} \frac{B S A_{i} \times M E T_{j} \times t_{i, j}}{24}[\mathrm{~W}]
$$

where $B S A_{i}$ is the body surface area $\left[\mathrm{m}^{2}\right]$ of i-person, $M E T_{j}$ is the metabolic equivalent of the task for $\mathrm{j}$-activity $[-], t_{i, j}$ is the daily mean time spent by i-person on $\mathrm{j}$-activity $[\mathrm{h}], 24$ is the number of hours per day.

\subsubsection{Occupational Latent Heat}

Calculation of the latent metabolic heat load requires air temperature, humidity, and minute ventilation of each individual subject to be taken into account. A determination of minute respiration as a function of heart rate during a range of physical activities was not a part of our experiment; thus, we decided to apply a simplified method, used by Simonsen et al. [16]. In addition to respiration and sweat, they also accounted for water vapour released due to hygiene activities, food preparation, experiments, and laundry. They assumed, that a lunar base crew will produce $3.24 \mathrm{~kg} / \mathrm{man}$-day of water vapour. Since the value includes not just the latent heat resulting from metabolic activities, but also other human habitation related phenomena, we decided to refer to this heat source as occupational latent heat. If base interior air humidity is to be kept at a constant level, this water vapour must eventually condense, releasing its latent heat due to phase change. Assuming a six-personnel crew and the latent heat of water evaporation at $23{ }^{\circ} \mathrm{C}$ equalling $2446 \mathrm{~kJ} / \mathrm{kg}$, the daily mean occupational latent heat load $\mathrm{Q}_{\mathrm{OLH}}=550 \mathrm{~W}$. Total daily mean occupational heat load was calculated as the sum of its two components:

Equation (5). Total occupational heat load.

$$
Q_{O c c}=Q_{S B H}+Q_{O L H}[\mathrm{~W}]
$$

\subsection{Heat Load from Energy Storage System}

Because of the relatively slow rotation of the moon, an average lunar day (synodic month) lasts 29.531 earth days [18]. It implies, that the solar-powered lunar base must be equipped with an energy storage solution of considerable capacity, which would guarantee the functioning of a base for more than the two-week-long lunar nights. An alternative solution would be to apply a nuclear power source, but we decided not to consider it in this analysis. Instead, we performed a study for two alternative energy storage solutions: hydrogen regenerative fuel cells (RFC) and Lithium-ion batteries (Li-ion). The RFC produces gaseous hydrogen and oxygen via water electrolysis (regeneration cycle) and feeds the stored gases into a fuel cell to produce electricity (discharge cycle). Li-ion batteries are also charged by applied direct current, but undergo completely different electrochemical reactions. The most notable advantage of RFCs is their exceptionally high specific energy, but they have relatively low roundtrip energy efficiency, resulting in considerable waste heat production [13,26,42]. Lithium-ion batteries have a much lower specific energy than RFCs, but their high round trip energy efficiency and stable performance in real-life duty cycles result in their successful application aboard the ISS [13,43,44]. Selected properties of the considered energy storage systems are compared in Table 4 . 
Table 4. Notable properties of the studied energy storage systems.

\begin{tabular}{ccc}
\hline Property & RFCs & Li-ion \\
\hline$\eta_{\text {RT }}$ round trip energy efficiency & $50 \%$ & $90 \%$ \\
$\eta_{\text {reg }}$ energy efficiency of the regenerative cycle & $90 \%$ & $94 \%$ \\
$\eta_{\text {DIS }}$ energy efficiency of the discharge cycle & $55 \%$ & $95 \%$ \\
e specific energy [Wh/kg] & 780 & 250 \\
\hline
\end{tabular}

RFCs, Regenerative Fuel Cells; Li-ion, Lithium-ion; RT, Round Trip; reg, regenerative cycle; DIS, discharge cycle.

In both cases, we assumed, that during lunar day the base photovoltaic power plant meets the station's instantaneous power demand without the need for energy buffering. Regenerative cycles are slowly accomplished during lunar days and energy storage undergoes full discharge during lunar nights. Therefore, the lunar daytime heat load from the energy storage regeneration cycle may be calculated as:

Equation (6). Lunar daytime heat load from the energy storage system [45].

$$
Q_{E S S, L D}=\frac{P_{A E D, L N}}{\eta_{R T}} \times\left(1-\eta_{r e g}\right)[\mathrm{W}]
$$

while lunar nighttime waste heat production in the discharge cycle may be calculated as:

Equation (7). Lunar nighttime heat load from the energy storage system [45].

$$
Q_{E S S, L N}=\frac{P_{A E D, L N}}{\eta_{d i s}} \times\left(1-\eta_{\text {dis }}\right)[\mathrm{W}]
$$

where $\eta_{R T}$ is the round trip efficiency of the energy storage system, $\eta_{\text {reg }}$ is the efficiency of the regenerative cycle, $\eta_{D I S}$ is the efficiency of the discharge cycle, and $P_{A E D, L N}$ is the lunar night-time daily mean power demand of active electric devices [W]. It is not possible to perform a complete, reliable determination of $P_{A E D, L N}$ without data concerning the energy demand of the thermal control system (TCS) of a lunar base. The very TCS does not, by definition, contribute directly to the total internal heat gains, but its operation during lunar nights influences the energy storage capacity and waste heat production of the ESS. The electric power demand of the TCS depends on the system's performance and applied cooling load. The latter depends on many variables, e.g., on selenographic latitude, site lighting conditions, size and architecture of the base, structure of its envelope, but most importantly on the total internal heat gain of the facility $[13,15,17,18,26,27]$. As the total internal heat gain depends indirectly on the TCS power demand and vice versa, an iterative approach to the solution of this problem was required. Thus, we initially assumed $P_{A E D, L N, 0}$ as just the sum of heat loads of all electrically powered devices, excluding the TCS:

Equation (8). Initial electric power demand of active electric devices during lunar night.

$$
P_{A E D, L N, 0}=Q_{B E}+Q_{P D}+Q_{S D}[\mathrm{~W}]
$$

where $Q_{B E}$ is the heat load from base equipment, $Q_{P D}$ is the heat load from the crew's personal devices, and $q_{S D}$ stands for heat load from supplementary equipment, including the power demand of the communication system external components. Calculation of the initial $P_{A E D, L N, 0}$ allowed determination of the initial heat loads of the energy storage systems $Q_{E S S, 0}$ (Equations (6) and (7)). That enabled obtaining the initial value of total internal heat gains in the base $\left(Q_{i n t, 0}\right)$.

Equation (9). Initial total internal heat gains in the base.

$$
Q_{\text {int }, 0}=P_{A E D, L N, 0}+Q_{O C C}+Q_{E S S, 0}[\mathrm{~W}]
$$

As $Q_{i n t, 0}$ was calculated, we needed to determine the external heat gains and losses for lunar days and nights, respectively. Based on the analysis performed by Simonsen et al. we assumed a 
constant solar gain for the base interior $\mathrm{q}_{\mathrm{ext}, \mathrm{LD}}=20 \mathrm{~W} / \mathrm{m}^{2}$ and a constant lunar nighttime heat losses $\mathrm{q}_{\mathrm{ext}, \mathrm{LN}}=-15.47 \mathrm{~W} / \mathrm{m}^{2}$. These values have been established for low-latitudinal lunar locations for a surface building covered with multilayer insulation that prevents excessive solar gain. Due to the specificity of the lunar surface environment, these assumptions are relatively accurate, simplify the calculations, and provide moderately conservative results. In comparison with these loads, conductive heat exchange with the lunar regolith was considered as negligibly low. As LUNARES has about $260 \mathrm{~m}^{2}$ of exposed exterior surface, its lunar daytime external heat loads $\mathrm{Q}_{\mathrm{ext}, \mathrm{LD}}$ would be about $5206 \mathrm{~W}$ and $\mathrm{Q}_{\mathrm{ext}, \mathrm{LN}}=-4023 \mathrm{~W}$ during lunar days and nights, respectively. Using these values, the Initial cooling loads of the TCS were calculated as follows:

Equation (10). Initial cooling load of the TCS.

$$
Q_{C L, 0}=Q_{\text {int }, 0}+Q_{\text {ext }}[\mathrm{W}]
$$

An Active Thermal Control System aboard the ISS requires $8.72 \mathrm{~kW}$ at its maximum cooling load that equals $70 \mathrm{~kW}[13,46]$. It gives maximum cooling load to total power consumption ratio equal to 8.03. This value is not to be confused with the coefficient of performance (COP), as the total power consumption of the system includes power demands on its many various subsystems. We named the value total performance ratio of a TCS (TPR). We assumed the same TCS performance ratio for the studied base and calculated its initial TCS electric power demand:

Equation (11). Power demand of the base TCS.

$$
P_{T C S, 0}=\frac{Q_{C L, 0}}{T P R}[\mathrm{~W}]
$$

The calculated $P_{T C S}$ was added to the previously calculated initial $P_{A E D, L N, 0}$, and the whole procedure has been repeated. In the fourth iteration a satisfactory agreement was reached, i.e., relative differences in $P_{T C S}$ between two consecutive iterations were less than $0.5 \%$. All the calculations described in this subsection were performed for four combinations: for RFCs and Li-ion batteries, during lunar days and lunar nights.

\section{Results and Discussion}

\subsection{Electric Devices}

\subsubsection{Existing Base Equipment}

Table 5 presents heat loads from the miscellaneous lunar base equipment described in Section 2.3. The total value equals almost $1.2 \mathrm{~kW}$ and gives a heat load per unit of floor surface $\mathrm{q}_{\mathrm{BE}}$ as high as $9.56 \mathrm{~W} / \mathrm{m}^{2}$. This value alone constitutes a significantly higher heat load than total internal heat gains in residential buildings on Earth [6,47]. Lim and Rao, 1984 [48] state, that lighting and other office appliances in densely occupied multi-storey office buildings in Singapore produce a heat load as high as $25 \mathrm{~W} / \mathrm{m}^{2}$ during working hours, which translates into a daily mean value of $9.37 \mathrm{~W} / \mathrm{m}^{2}$. This demonstrates, that in a lunar base, the daily mean heat load from this class of electric devices is of a comparable value with densely occupied offices, rather than with residential buildings. 
Table 5. Heat load from the base equipment.

\begin{tabular}{|c|c|c|c|c|c|}
\hline Compartment & Device & Quantity & $\begin{array}{l}\text { Mean Power } \\
\text { Demand [W] }\end{array}$ & $\begin{array}{c}\text { Mean Daily } \\
\text { Use [h] }\end{array}$ & $\begin{array}{l}\text { Daily Mean Heat } \\
\text { Generation [W] }\end{array}$ \\
\hline 1 & 3D printer & 1 & 700 & 12 & 350 \\
\hline 6 & air compressor & 1 & 3.5 & 24 & 3.5 \\
\hline 8 & airlock status LEDs & 2 & 5 & 24 & 10 \\
\hline 8 & artificial daylight LEDs & 1 & 150 & 24 & 150 \\
\hline 3 & domestic water electric heater & 1 & 2200 & 0.033 & 3.025 \\
\hline 7 & domestic water electric heater & 1 & 4000 & 0.62 & 103.33 \\
\hline 3 & induction oven & 1 & 2000 & 0.25 & 20.83 \\
\hline all but 7 & interior monitoring camera $9 \times$ & 9 & 5 & 24 & 45 \\
\hline 1 & Laptop & 1 & 60 & 12 & 30 \\
\hline 5 & laser printer & 1 & 800 & 0.03 & 1.11 \\
\hline 8 & 65" LCD display & 1 & 160 & 24 & 160 \\
\hline all but 8 & lighting LED lamps & 33 & 20 & 4 & 110 \\
\hline 1 & magnetometer battery charger & 1 & 4 & 0.14 & 0.0024 \\
\hline 6 & microcentrifuge $(4 \times)$ & 4 & 3 & 24 & 12 \\
\hline 3 & microwave & 1 & 800 & 0.75 & 25 \\
\hline 6 & plant lighting type $\mathrm{A}$ & 1 & 10 & 24 & 10 \\
\hline 6 & plant lighting type $B$ & 2 & 16 & 24 & 32 \\
\hline 6 & plant lighting type $\mathrm{C}$ & 3 & 32 & 24 & 96 \\
\hline 3 & Projector & 1 & 60 & 0.5 & 1.25 \\
\hline 5 & SocSenSys devices & 1 & 20 & 24.00 & 20 \\
\hline 1 & soldering iron & 1 & 100 & 0.083 & 0.34 \\
\hline 1 & spectrometer & 1 & 20 & 2 & 1.67 \\
\hline & & & & \multicolumn{2}{|c|}{ in total $\mathrm{Q}_{\mathrm{BE}}=1185.06$} \\
\hline
\end{tabular}

LED, Light-Emitting Diode; LCD, Liquid Crystal Display; SocSenSys, Social Sensing System.

\subsubsection{Crew's Personal Devices}

The list of the crew's personal devices and their contributions to IHG are presented in Table 6.

Table 6. Heat load from the crew's personal devices.

\begin{tabular}{cccc}
\hline Name & Nominal Power Input [W] & Mean Daily Use [h/day] & Daily Mean Heat Generation [W] \\
\hline Laptop 1 & 65 & 9 & 24.38 \\
Camera & 10 & 2 & 0.83 \\
e-book reader & 5 & 0.25 & 0.05 \\
Laptop 2 & 80 & 6 & 20.00 \\
Camera & 10 & 0.5 & 0.21 \\
Smartphone & 2 & 0.2 & 0.02 \\
IR camera & 10 & 0.25 & 0.10 \\
Laptop 3 & 60 & 2 & 5.00 \\
Smartphone & 2 & 1 & 0.08 \\
Laptop 4 & 80 & 10 & 33.33 \\
mp3 player & 5 & 2 & 0.42 \\
Laptop 5 & 65 & 8 & 21.67 \\
Laptop 6 & 70 & 2 & 5.83 \\
Smartphone & 5 & 5 & 1.04 \\
& & & in total Q \\
\end{tabular}

\section{IR, Infrared}

Most of these devices have either low power demands or were relatively rarely used. The total mean heat load from this group of internal heat sources $(0.11 \mathrm{~kW})$ is relatively low and have no significant effect on the total internal heat gain in the base.

\subsubsection{Supplementary Devices}

Table 7 lists all the systems necessary to ensure the proper functioning of the base in the lunar environment. Additional inventory for long term habitation, maintenance and laboratory equipment for accomplishing an enhanced research plan are listed there as well. 
Table 7. Heat load from supplementary devices.

\begin{tabular}{cccc}
\hline Device & $\begin{array}{c}\text { Nominal Power Input } \\
{[\mathbf{W}]}\end{array}$ & $\begin{array}{c}\text { Daily Use } \\
{[\text { h/day] }}\end{array}$ & $\begin{array}{c}\text { Daily Mean Heat } \\
\text { Generation [W] }\end{array}$ \\
\hline $\begin{array}{c}\text { Environmental control and life } \\
\text { support systems }\end{array}$ & 4500 & 24 & 4500.00 \\
\hline Airlock vacuum pump & 500 & 0.083 & 1.74 \\
\hline Spacesuit battery charger & 140 & 6 & 10.50 \\
\hline Sample drill battery charger & 2000 & 1 & 25.00 \\
\hline $\begin{array}{c}\text { Communication system internal } \\
\text { components }\end{array}$ & 1500 & 24 & 1500.00 \\
\hline Communication system external \\
components
\end{tabular}

This group of internal heat sources provides a substantial contribution to the total internal heat gain. The largest contributions come from the life support and communication systems, as they are relatively high-power systems and they function continuously. Out of the total $2.5 \mathrm{~kW}$ total power demand of the communication system, $1 \mathrm{~kW}$ is consumed by its external components (mostly by a transmission laser) [32], so only $1.5 \mathrm{~kW}$ is expended inside the base envelope and may be accounted as internal heat load. The total power demand of electric devices listed in this subsection equals $7.88 \mathrm{~kW}$, which yields $\mathrm{q}_{\mathrm{SD}}=58 \mathrm{~W} / \mathrm{m}^{2}$. This value is unrivalled by the total heat gains in neither residential nor office buildings, but is comparable with the internal heat gains in many industrial facilities $[49,50]$.

The three discussed components of the heat load from electrical devices were compared in Figure 3.

It is to be noticed, that about $76 \%$ of the total electric devices heat load is generated by the interplanetary communication and life support systems. 


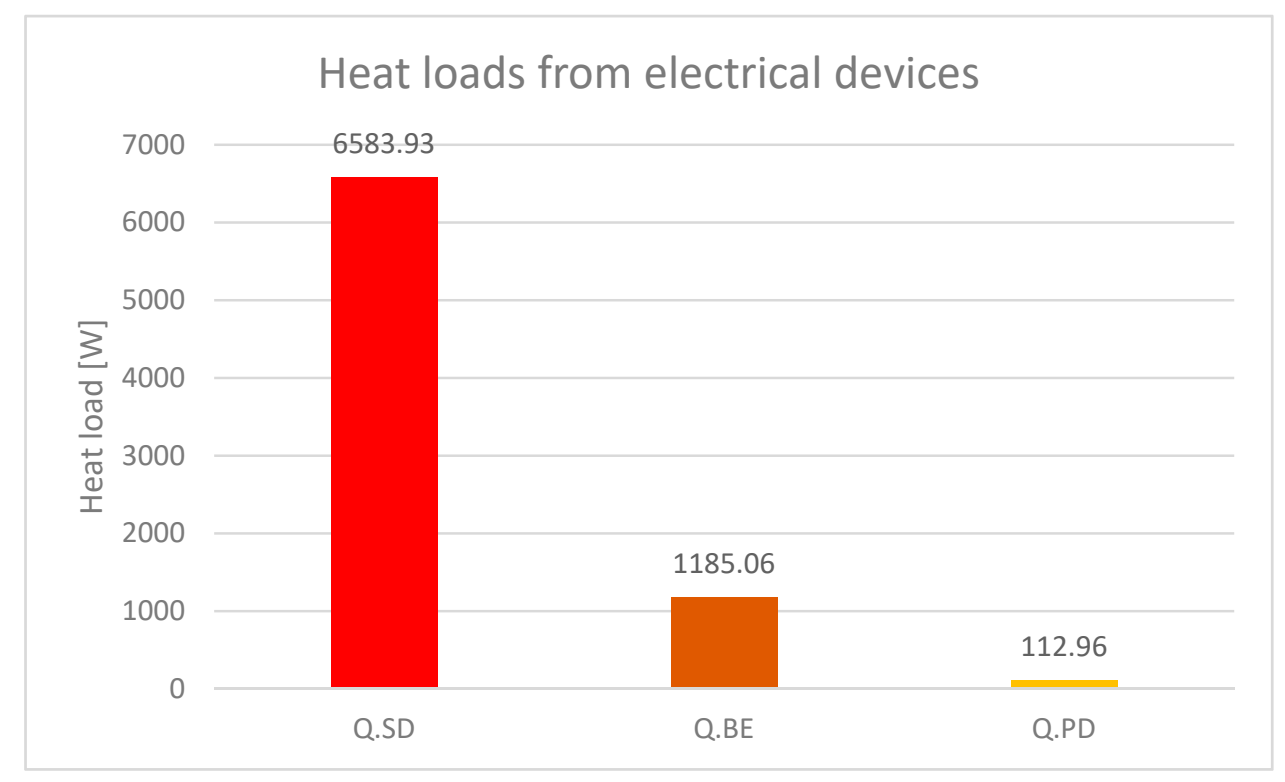

Figure 3. Heat loads from electrical devices.

\subsection{Occupational Heat Loads}

Tables 8 and 9 present the daily mean sensible body heat production by the ICAres- 1 crew for lunar days and lunar nights, respectively. It is noticeable, that during a lunar day, the total time spent by crew members inside the base does not add up to $24 \mathrm{~h} /$ day due to EVAs.

Table 8. Daily crew activities during lunar days.

\begin{tabular}{ccccc}
\hline \multirow{2}{*}{ Crew Member } & \multicolumn{2}{c}{ Daily Time Spent on Activities [h] } & \multirow{2}{*}{$\begin{array}{c}\text { Daily Mean Sensible Heat } \\
\text { Generation [W] }\end{array}$} \\
\cline { 2 - 4 } & PA-1 & PA-2 & PA-3 & 132.62 \\
A & 9 & 12.5 & 1.75 & 129.49 \\
B & 9 & 13 & 1.25 & 151.10 \\
C & 9 & 12.75 & 1.5 & 147.63 \\
D & 9 & 13 & 1.25 & 149.51 \\
E & 9 & 13 & 1.25 & 185.69 \\
F & 9 & 11.5 & 2.75 & in total: Q Q \\
& & & &
\end{tabular}

$\mathrm{Q}_{\mathrm{SBH}, \mathrm{LD}}$-Total daily mean sensible heat generation during lunar days.

Table 9. Daily crew activities during lunar nights.

\begin{tabular}{ccccc}
\hline Crew Member & \multicolumn{3}{c}{ Daily Time Spent on Activities [h] } & Daily Mean Sensible Heat \\
\cline { 2 - 4 } Generation [W]
\end{tabular}

$\mathrm{Q}_{\mathrm{SBH}, \mathrm{LN}}$-Total daily mean sensible heat generation during lunar nights.

Sensible body heat production during lunar night is about $5.6 \%$ higher than during lunar days, as the crew spend more time and perform more PA-3 inside the base. Despite increased physical activities, crew metabolic processes would generate about $19 \%$ less heat load on the Moon than in 
terrestrial conditions during the ICAres-1 mission [28]. In order to enable a better comparison of lunar and terrestrial metabolic heat generation, the daily mean MET values were calculated for the same physical activities schedules for both the Earth and the Moon. In the case of "lunar day" activities (Table 8), daily mean metabolic rates were 1.69 and 1.38 for the Earth and the Moon, respectively; while for "lunar night" (Table 9) the respective values were 1.83 and 1.46. It may be observed, that the more vigorous physical activities that are scheduled, the more pronounced the differences in the mean metabolic heat loads become between the actual lunar base and its terrestrial analogue. It remains a subject of a different study, whether the activities for the astronauts on the Moon should be adjusted to match their terrestrial daily mean metabolic rates. In comparison with terrestrial houses or offices, the studied base has a rather moderate occupancy density of 0.044 people $/ \mathrm{m}^{2}$, but is almost constantly fully staffed, which is not the case in most of the buildings on earth. In the studied lunar base, the average metabolic sensible heat load per unit of floor surface $\mathrm{q}_{\mathrm{sBH}}$ equals $6.8 \mathrm{~W} / \mathrm{m}^{2}$. This situates the result between the metabolic heat loads for residential buildings and for offices $[6,47,48]$. It is important to observe, that in the case of terrestrial buildings, occupational latent heat loads are usually ignored in the calculations, as typical ventilation systems dispose of the excess humidity without latent heat recovery. In a closed-loop lunar facility, all the excess moisture will be condensed. In that case,

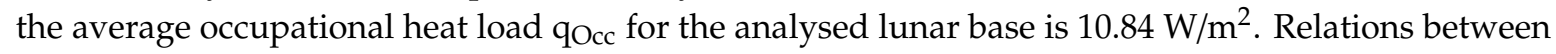
occupational heat load and its components are depicted in Figure 4.

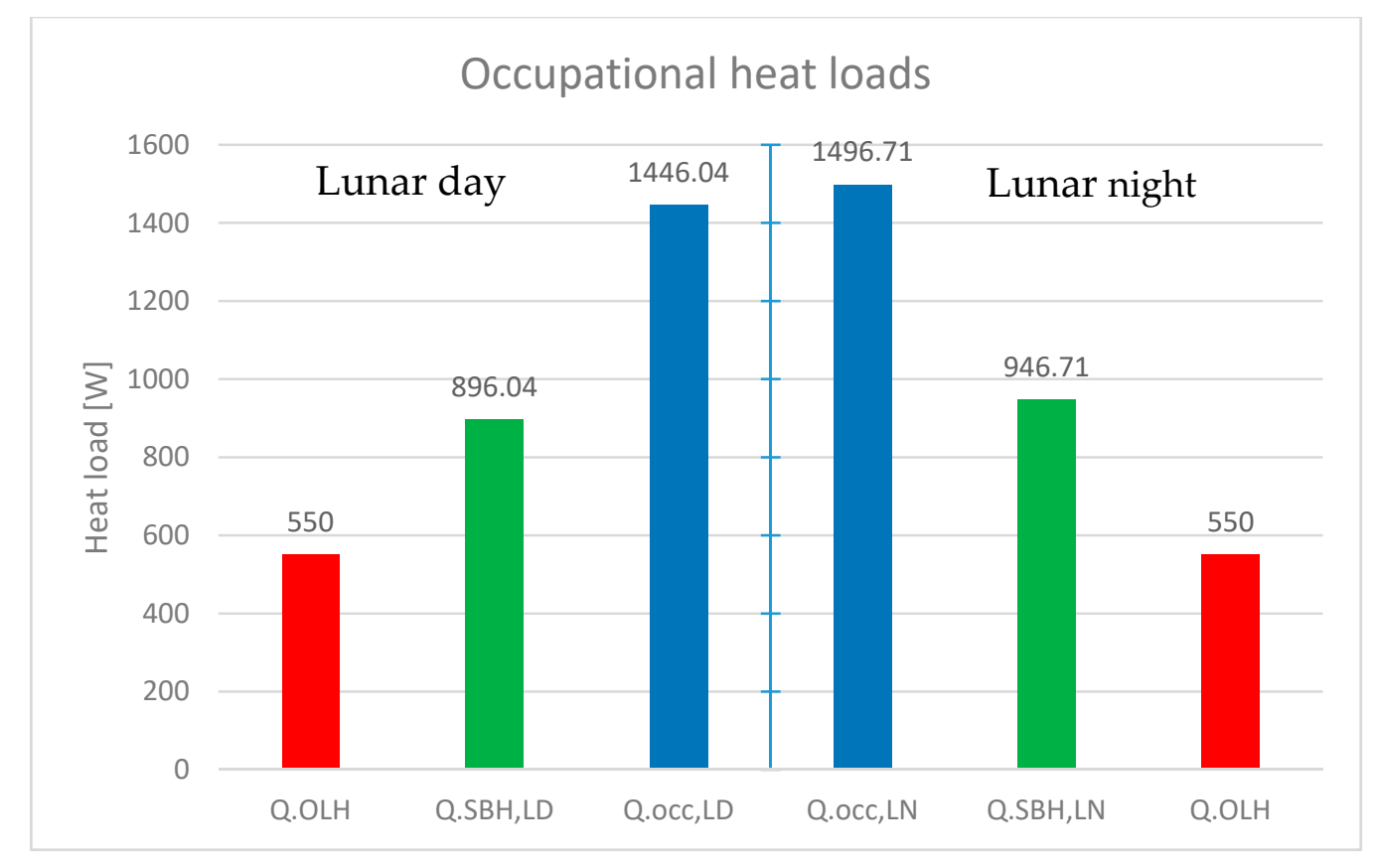

Figure 4. Total occupational heat loads and its components.

According to Kim et al. 2018 [48], considerable differences in occupancy-related heat loads are observed between office buildings in East Asia and North America. The average values during working hours are 14.84 and $6.18 \mathrm{~W} / \mathrm{m}^{2}$, respectively. Assuming a nine-hour working hour day, the respective daily mean values are 5.57 and $2.32 \mathrm{~W} / \mathrm{m}^{2}$. It is clear then, that the lunar base would exhibit much higher daily mean occupational heat loads than either residential or office buildings on Earth.

\subsection{Energy Storage System}

According to the calculation algorithm presented in Section 2.5, the final values of the cooling loads for the TCS must have been determined in the first place. The results are presented in Table 10. 
Table 10. Cooling loads for the base thermal control system (TCS).

\begin{tabular}{ccc}
\hline \multirow{2}{*}{ Energy Storage } & \multicolumn{2}{c}{ Cooling Load [W] } \\
\cline { 2 - 3 } & Lunar Day & Lunar Night \\
\hline RFC & $16,683.01$ & $14,055.37$ \\
Li-ion & $15,175.76$ & 5861.66 \\
\hline
\end{tabular}

Total cooling loads of the base TCS are significantly higher when RFCs are used instead of Li-ion batteries. This is due to the relatively low round trip energy efficiency of RFCs, which results in increased waste heat production by this ESS, which will be shown later. The total heat loads of the base, i.e., the cooling loads of the TCS, have a direct impact on TCS power demands, which are presented in Table 11.

Table 11. Power demand of the base TCS.

\begin{tabular}{ccc}
\hline \multirow{2}{*}{ Energy Storage } & \multicolumn{2}{c}{ Electric Power Consumption $[W]$} \\
\cline { 2 - 3 } & Lunar Day & Lunar Night \\
\hline RFC & 2078.23 & 1750.90 \\
Li-ion & 1890.47 & 730.20 \\
\hline
\end{tabular}

Establishing the thermal control systems' power demands allowed for a final determination of $P_{A E D, L N}$, which was $10.63 \mathrm{~kW}$ for RFCs and $9.61 \mathrm{~kW}$ for Li-ion batteries. Thanks to this, it was eventually possible to obtain the ESS heat loads. The comparison of waste heat generation by the two analysed energy storage systems are presented in Table 12.

Table 12. Heat loads from energy storage systems.

\begin{tabular}{ccc}
\hline \multirow{2}{*}{ Energy Storage } & \multicolumn{2}{c}{ Heat Load [W] } \\
\cline { 2 - 3 } & Lunar Day & Lunar Night \\
\hline RFC & 2148.05 & 8699.62 \\
Li-ion & 640.81 & 505.90 \\
\hline
\end{tabular}

Significant differences in waste heat generation may be observed between RFCs and Li-ion batteries. The differences are most pronounced during lunar nights, when the relatively low energy efficiency fuel cell discharge cycle is in operation. This imbalance between lunar days and nights heat loads for RFCs is primarily a result of notable differences in its energy efficiencies of regenerative and discharge cycles. In the case of Li-ion batteries, which recharge and discharge at almost the same rate, no such large differences in lunar day and night heat loads are observed. The existing difference between waste heat generation by Li-ion batteries for lunar day and night is the result of net efficiency losses for consecutive energy transformations.

\subsection{Total Internal Heat Gains}

The total internal heat gain depends on applied ESS, as well as on the time of lunar day. This dependence is presented in Table 13. 
Table 13. Total internal heat gains with different energy storage systems.

\begin{tabular}{ccccc}
\hline & \multicolumn{2}{c}{ RFC } & \multicolumn{2}{c}{ Li-ion } \\
\cline { 2 - 5 } & Lunar Day & Lunar Night & Lunar Day & Lunar Night \\
\hline Internal heat gains [W] & $11,476.41$ & $18,078.65$ & 9969.17 & 9884.93 \\
$\begin{array}{c}\text { Internal heat gains per unit } \\
\left.\text { of floor surface [W/m }{ }^{2}\right]\end{array}$ & 84.51 & 133.13 & 73.41 & 72.79 \\
\hline
\end{tabular}

In order to evaluate the individual contributions of the three main groups of internal heat sources to the total internal heat gain in the studied lunar base, the most important figures were compared in the Table 14 .

Table 14. Comparison of main internal heat sources in the base.

\begin{tabular}{ccc}
\hline Heat Source & Heat Load $[\mathbf{W}]$ & Heat Load per Unit of Floor Surface $\left[\mathbf{W} / \mathbf{m}^{\mathbf{2}}\right]$ \\
\hline Electric devices & 7881.97 & 58.04 \\
Occupation LD & 1446.39 & 10.65 \\
Occupation LN & 1497.06 & 11.02 \\
RFC LD & 2148.05 & 15.82 \\
RFC LN & 8699.62 & 64.06 \\
Li-ion LD & 640.81 & 4.72 \\
Li-ion LN & 505.90 & 3.73 \\
\hline
\end{tabular}

The data from Table 14 was also presented graphically in Figure 5.

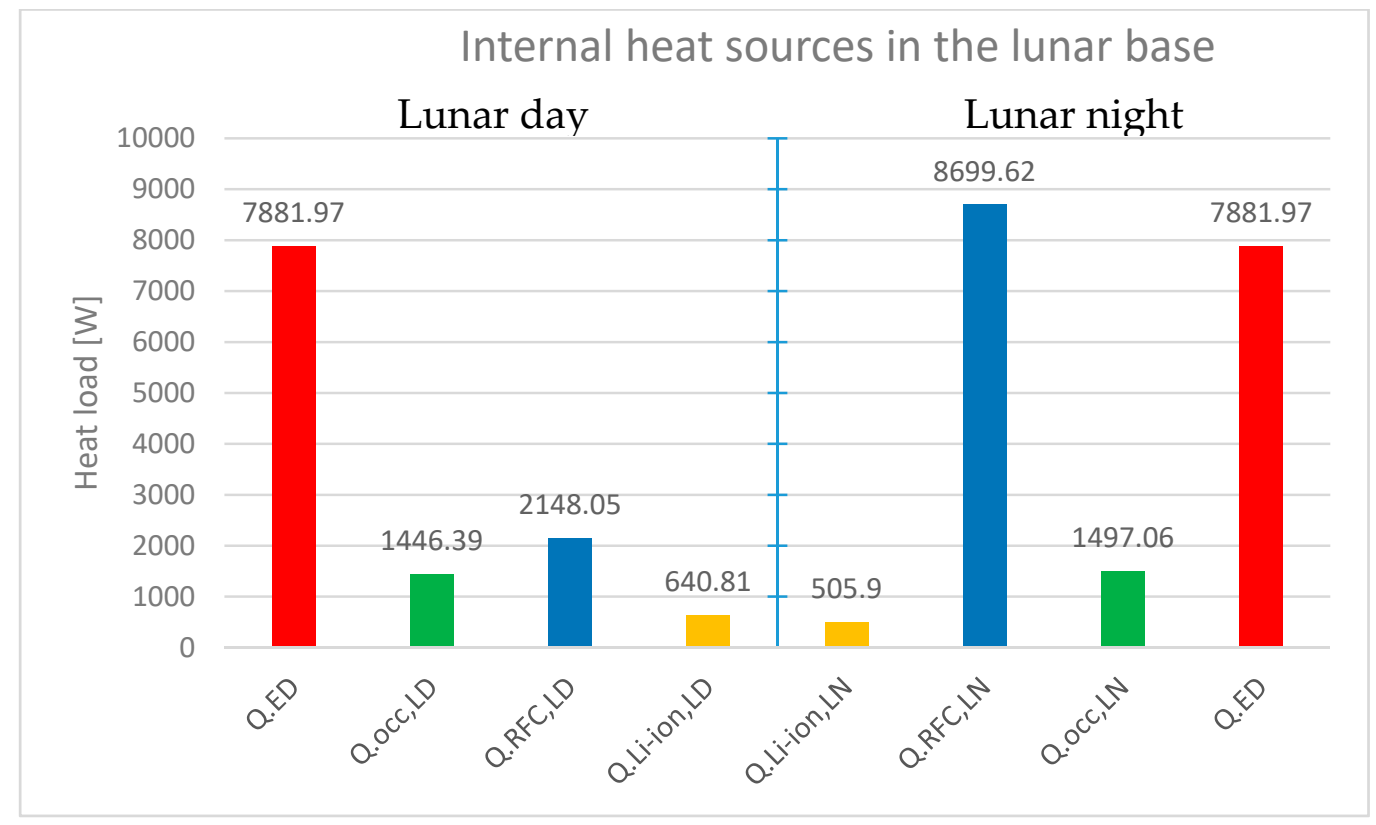

Figure 5. Internal heat loads in the lunar base during the lunar cycle.

It is clear, that an energy storage system based on RFCs constitutes the most significant potential contribution to total internal heat gain in a lunar building. If applied, this energy storage system would deliver $16 \%$ of IHG during lunar days and $44 \%$ during lunar nights. The respective values for Li-ion batteries are $3.23 \%$ and $2.55 \%$. In the lunar environment, that presents limited opportunities for excess heat dissipation; waste heat production by ESS should be minimized as much as possible, most especially in a situation where combined heat loads from occupancy and electric devices already give almost $70 \mathrm{~W} / \mathrm{m}^{2}$. The daily mean IHG of the studied lunar base is definitely higher than the 
respective values for residential and office buildings, but are comparable with IHG of some industrial facilities [6,47-50]. On the other hand, the discussed value is far less than the $250 \mathrm{~W} / \mathrm{m}^{2}$ assumed by [16]. The primary explanation of this difference may be that the authors of the mentioned work used the baselines for orbital space stations, where, in zero-g, all the interior surfaces of the cylindrical modules may be stacked with equipment without creating any accessibility issues for its crew. It is clear, that this is not the case in a situation when a base crew are subjected to lunar gravity, and must stand on the floor. In addition to that, our base inventory consists of contemporary devices with much lover energy consumption than the state-of-the-art devices in the late 1980s.

\subsection{Parametric Study}

\subsubsection{Overall Assumptions}

We consider the results presented in Sections 3.1-3.4 as the nominal operation parameters for the studied base. These values served as a reference for the parametric study conducted in this paragraph. We nominated five variable parameters for the evaluation:

- number of occupants (the base crew);

- mean body surface area of the crew;

- intravehicular physical activity profile;

- $\quad$ power demand of electrical devices, representing potentially variable base inventory and its use;

- $\quad$ type of applied ESS.

Based on LUNARES specifications, we assumed, that the studied lunar base and its systems were designed to accommodate and support up to a six-personnel crew and no additional crew members are to be accommodated on board. In order to ensure the crew's safety and their adequate work efficiency within the base system's limitations, without compromising their personal comfort, the base must be staffed with three to six astronauts. It is also worth considering, that the base may remain periodically uninhabited.

An increase in occupancy-related heat load might appear if it is found that performing additional physical exercises will be necessary to keep the crew in adequate physical condition. On the other hand, temporarily reducing daily exercise may be allowed for the benefit of other duties if such a need arises. The problem was addressed by transferring the time between the PA-2and PA-3 categories in the daily timetable. The calculation method for the total occupational heat load was modified to simplify addressing variable mean body surface areas for the different crews that will occupy the base.

Considering possible variations in the heat load of electrical devices, we assumed no vital system failures, as it would compromise the functioning of the base and lead to immediate evacuation of the crew. We, however, assumed electrical power demand reduction, as some non-vital equipment may fail or become temporarily unused for any other reason. Of course, the base electrical system must, to some extent, allow powering additional equipment or increasing the use of already-existing devices; what which has also been addressed. We assumed, that when the base remains uninhabited, no electrically-powered experiments are left to be automatically or remotely conducted without actual crew supervision. Even an uninhabited base must remain pressurised and maintain a near-normal interior temperature, as numerous devices are susceptible to variations in these parameters. Any changes of internal heat gains has an influence on the temperature control and energy storage systems; which has also been taken into account. All of these parameters are interconnected and have an influence on each other; and which is represented in our detailed assumptions.

\subsubsection{Detailed Assumptions and Parameter Range}

- Occupational Heat Load

According to the overall assumptions, the number of the base inhabitants must be either 0 or be between 3 and 6 . As the differences in lunar day and lunar night occupational heat loads turned 
out to be relatively minor, we decided to abandon this division and to use the daily mean physical activity schedule instead. We also decided not to calculate sensible body heat individually for each crew member, as was done before, but to characterise the whole crew by assuming the mean body surface area and the number of its members. For example, the ICAres- 1 crew may be characterised by the set of parameters presented in Table 15.

Table 15. Parameters characterizing ICAres- 1 crew.

\begin{tabular}{ccc}
\hline Symbol & Description & Value \\
\hline $\mathrm{CN}$ & number of crew members & 6 \\
BSA $_{\text {mean }}$ & mean body surface area of the crew & $1.86 \mathrm{~m}^{2}$ \\
PA-1 & time spent on sleep and relaxation & $9.00 \mathrm{~h} /$ day \\
PA-2 & time spent on light, mostly sedentary activities & $12.63 \mathrm{~h} /$ day \\
PA-3 & time spent on exercises and moderate intensity activities & $2.00 \mathrm{~h} /$ day \\
\hline
\end{tabular}

The time in the table does not add up to $24 \mathrm{~h} /$ day due to EVAs. Mean occupational heat load (sensible + latent) is to be calculated with Equation (12):

Equation (12). Daily mean occupational heat load

$$
Q_{o c c, \text { mean }}=C N \times\left(B S A_{\text {mean }} \times \sum_{i} \frac{M E T_{i} \times t_{i}}{24}+\frac{Q_{O L H}}{6}\right)[W]
$$

where $C N$ is the number of crew members, $B S A_{\text {mean }}$ is the mean body surface area $\left[\mathrm{m}^{2}\right]$ of the crew members, $M E T_{i}$ is the metabolic equivalent of the task for i-activity [-], $t_{i}$ is the daily mean time spent by the crew on i-activity [h], 24 is the number of hours per day.

Using Equation (12) and the parameters from Table 15, we obtained $Q_{o c c, \text { mean }}=1471.73 \mathrm{~W}$, which matches $\frac{Q_{S B H, L D}+Q_{S B H, L N}}{2}+Q_{O L H}$.

Adapting this approach to occupational heat load offered more clarity for data presentation and gave better control over the calculation process.

According to [51] the average body surface area for adult men and women is $1.9 \mathrm{~m}^{2}$ and $1.6 \mathrm{~m}^{2}$, respectively. Despite the continuous increase in the percentage of female astronauts, this trait remains male-dominated [52]. One of the most important limitations for long-term female space missions is their relatively high susceptibility for ionizing radiation exposure [53]. Since the surface of the Moon is exposed to primary cosmic rays, it is to be expected, that women will constitute a minority in near-future lunar missions. We therefore assumed $1.75 \mathrm{~m}^{2} \leq \mathrm{BSA}_{\text {mean }} \leq 1.95 \mathrm{~m}^{2}$. Considering the fact that the astronauts onboard the ISS exercise approximately two hours per day [54], we assumed 1 h/day $\leq$ PA-3 time $\leq 3 \mathrm{~h} /$ day. Daily activity timetables are to be balanced between PA- 2 and PA-3 time, leaving PA-1time unchanged.

- Electrical Devices Heat Load

This parametric study required applying a different approach for assessing the heat load of electrical devices. A new division for electrical devices was made according to their power demand profiles, i.e., on how the power demand of a device is affected by the actual number of base occupants. All the electrical devices presented in Tables 5-7 were divided into the three following categories:

- $\quad$ habitation dependent (HD) power demand: devices belonging to this category are either fully operational and constantly use nominal power when the base is inhabited, or are completely deactivated when the base remains temporarily uninhabited;

- occupancy independent or partially dependent: these devices operate continuously, but their instantaneous power demand may, to some extent, depend on the actual number of base occupants;

- fully dependent (FD) on occupancy: the daily mean power demand of these devices is directly proportional to the actual number of base occupants. 
All habitation-dependent base electrical devices are presented in Table 16.

Table 16. Habitation-dependent electrical devices in the lunar base.

\begin{tabular}{cc}
\hline Device & Mean Power Demand [W] \\
\hline air compressor & 3.5 \\
airlock status LEDs & 5 \\
artificial daylight LEDs & 150 \\
65" LCD display & 160 \\
Microcentrifuge (4x) & 3 \\
plant lighting type A & 10 \\
plant lighting type B & 16 \\
plant lighting type C & 32 \\
projector & 60 \\
refrigerator & 10.00 \\
washing machine & 2000 \\
\hline
\end{tabular}

For the occupancy independent or partially dependent devices we devised a formula that allows calculating their power demand as a function of the actual number of base inhabitants:

Equation (13). Daily mean power demand of an IPD device

$$
Q_{I P D, i}=P_{n o m, i} \times\left(\left(1-O D F_{i}\right)+O D F_{i} \times \frac{C N}{6}\right)[W]
$$

where: $Q_{I P D, I}$ daily mean power demand of an i-device, $P_{n o m, i}$ is the nominal power of an i-device (see: Tables 6-8), $C N$ is the current number of base inhabitants and $O D F_{i}$ stands for the occupancy dependence factor of an i-device. For ODF $=0$ the device is occupancy-independent, operating continuously at its nominal power. If $0<\mathrm{ODF}<1$ the device runs continuously at least at threshold power, and its daily mean power demand increases with occupancy. With ODF $=1$, the device falls into the third category (FD).

Table 17 lists all the base devices that belong to the "occupancy independent or partially dependent" category, along with their estimated ODFs. Note the fact that communication system external components contribute to the total electrical power demand, but not to the total IHG.

Table 17. Occupancy independent or partially dependent electrical devices in the lunar base.

\begin{tabular}{ccc}
\hline Device & Mean Power Demand [W] & ODF Occupancy Dependence Factor \\
\hline Interior monitoring camera 9x & 5 & 0 \\
SocSenSys devices & 20 & 0.9 \\
Environmental Control and Life Support Systems & 4500 & 0.85 \\
Communication system internal components & 1500.00 & 0.66 \\
Communication system external components & 1000.00 & 0.7 \\
Central computer & 100.00 & 0.3 \\
Electrical Power Systems & 200 & 0.65 \\
\hline
\end{tabular}

Devices not included in Table 16 or Table 17 belong to the FD category. This group includes daylighting, appliances, laboratory, and maintenance equipment.

Heat loads from each category of electrical devices for nominal operation parameters of the base are depicted in Figure 6. 


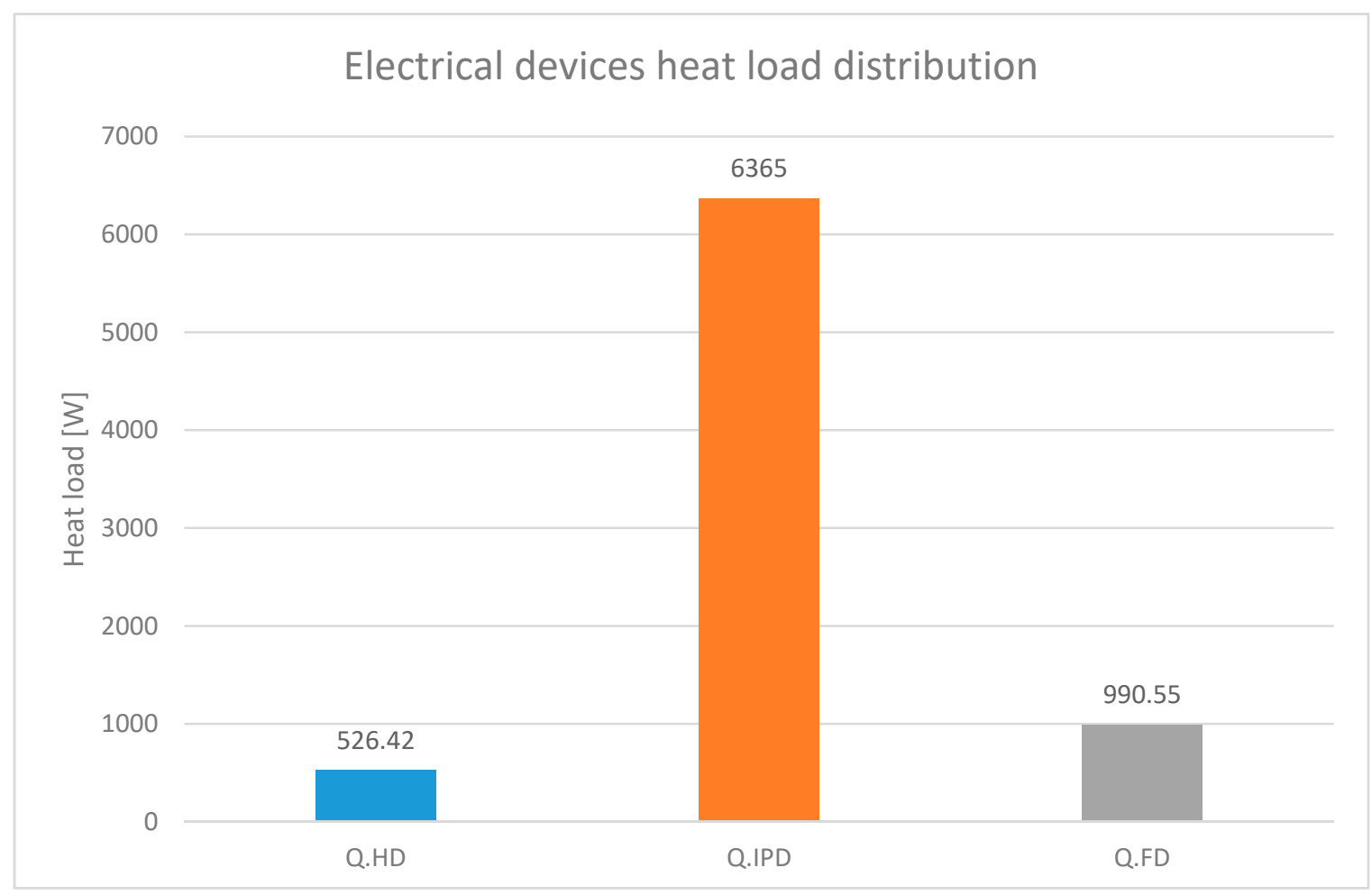

Figure 6. Nominal operations heat load distribution for the three categories of electrical devices.

These heat loads add up to $\mathrm{Q}_{\mathrm{ED}}=7881.97 \mathrm{~W}$. It is to be observed, that in this reference configuration, over $80 \%$ of this heat load is generated by the base's vital systems, and only about $13 \%$ results from crew equipment use. Nonetheless, the latter may be subjected to relatively high variations, e.g., due to actual research requirements. For this parametric study we assumed, that the total heat load of the devices that belong to the FD category may vary according to the following equation:

Equation (14). Daily mean heat load from the FD electrical devices as a function of occupancy and power demand coefficient.

$$
Q_{F D}=C_{P D} \times C N \times \sum_{i} \frac{P_{\text {nom }, i}}{6}
$$

where $C N$ is the actual number of base occupants, $P_{\text {nom, } i}$ is the nominal power of an i-device, and $C_{P D}$ is the power demand coefficient. We assumed $C_{P D}$ to range between 0.5 and 3 .

\section{- Temperature Control and Energy Storage Systems}

All the possible variations in occupational and electrical devices heat loads will influence the $P_{T C S}$ and, as a result, waste heat production by ESS. This issue has been addressed by means explained in 2.5. All the calculations were conducted for Li-ion and RFC based energy storage systems.

\subsubsection{Studied Combinations}

It was decided to perform parametric studies for the most characteristic combinations of analysed parameters. The combinations and their parameters are listed in Table 18.

Combination 1 is the reference (nominal) case elaborated in detail in Sections 3.1-3.4. Combinations 2-8 stand for calculations performed on the nominal configuration with single parameter modifications. In these cases the nominal parameter values were changed for both their assumed extremes. Combination 9 represents a temporarily uninhabited base, while cases 10 and 11 consider the most extreme combinations of all the parameters. 
Table 18. Parameters of studied combinations.

\begin{tabular}{|c|c|c|c|c|c|}
\hline \multicolumn{2}{|r|}{ Combination } & \multirow{2}{*}{$\begin{array}{l}\text { CN Number of } \\
\text { Inhabitants [-] }\end{array}$} & \multirow{2}{*}{$\begin{array}{c}\text { BSA }_{\text {mean }} \text { Body } \\
\text { Surface Area }\left[\mathrm{m}^{2}\right]\end{array}$} & \multirow{2}{*}{$\begin{array}{l}\text { Mean Time Spent } \\
\text { on PA-3 [h/day] }\end{array}$} & \multirow{2}{*}{$\begin{array}{l}\mathrm{C}_{\mathrm{PD}} \text { Power Demand } \\
\text { Coefficient [-] }\end{array}$} \\
\hline No & Description & & & & \\
\hline 1 & $\begin{array}{l}\text { max. crew number (nominal } \\
\text { parameters) }\end{array}$ & 6 & 1.86 & 2 & 1 \\
\hline 2 & min. crew number & 3 & 1.86 & 2 & 1 \\
\hline 3 & max. BSA.mean & 6 & 1.95 & 2 & 1 \\
\hline 4 & min. BSA.mean & 6 & 1.75 & 2 & 1 \\
\hline 5 & increased exercising & 6 & 1.86 & 3 & 1 \\
\hline 6 & reduced exercising & 6 & 1.86 & 1 & 1 \\
\hline 7 & increased power demand & 6 & 1.86 & 2 & 3 \\
\hline 8 & reduced power demand & 6 & 1.86 & 2 & 0.5 \\
\hline 9 & uninhabited base & 0 & - & - & - \\
\hline 10 & min. Parameters & 3 & 1.75 & 1 & 0.5 \\
\hline 11 & max. Parameters & 6 & 1.95 & 3 & 3 \\
\hline
\end{tabular}

3.5.4. Results and Discussion

Tables 19-21 presents the results of the parametric study.

Table 19. Table Heat loads in studied combinations.

\begin{tabular}{|c|c|c|c|c|c|c|}
\hline \multirow{4}{*}{ Combination } & \multicolumn{6}{|c|}{ Heat Loads [W] } \\
\hline & \multirow{3}{*}{$\begin{array}{l}\text { Occupational } \\
\text { Qocc,mean }\end{array}$} & \multirow{3}{*}{$\begin{array}{c}\text { Electrical } \\
\text { Devices }\end{array}$} & \multicolumn{4}{|c|}{ Energy Storage System } \\
\hline & & & \multicolumn{2}{|c|}{ RFC } & \multicolumn{2}{|c|}{ Li-ion } \\
\hline & & & Lunar Day & Lunar Night & Lunar Day & Lunar Night \\
\hline 1 & 1471 & 7882 & 2147 & 8697 & 641 & 506 \\
\hline 2 & 735 & 4890 & 1291 & 5229 & 385 & 304 \\
\hline 3 & 1517 & 7882 & 2149 & 8702 & 641 & 506 \\
\hline 4 & 1418 & 7882 & 2146 & 8691 & 640 & 505 \\
\hline 5 & 1494 & 7882 & 2148 & 8699 & 641 & 506 \\
\hline 6 & 1448 & 7882 & 2147 & 8694 & 640 & 506 \\
\hline 7 & 1471 & 9863 & 2648 & 10726 & 790 & 624 \\
\hline 8 & 1471 & 7387 & 2022 & 8189 & 603 & 476 \\
\hline 9 & 0 & 1372 & 480 & 1945 & 274 & 216 \\
\hline 10 & 698 & 4643 & 1227 & 4971 & 366 & 289 \\
\hline 11 & 1541 & 9863 & 2650 & 10734 & 791 & 624 \\
\hline
\end{tabular}

Table 20. Internal heat gains in the studied combinations.

\begin{tabular}{ccccc}
\hline \multirow{2}{*}{ Combination } & \multicolumn{4}{c}{ QINT Total Internal Heat Gain [W] } \\
\cline { 2 - 5 } & \multicolumn{3}{c}{ RFC } & \multicolumn{2}{c}{ Li-ion } \\
\cline { 2 - 5 } & Lunar Day & Lunar Night & Lunar Day & Lunar Night \\
\hline 1 & 11,500 & 18,049 & 9993 & 9858 \\
2 & 6917 & 10,855 & 6011 & 5930 \\
3 & 11,547 & 18,100 & 10,040 & 9905 \\
4 & 11,445 & 17,990 & 9940 & 9805 \\
5 & 11,524 & 18,075 & 10,016 & 9882 \\
6 & 11,477 & 18,024 & 9971 & 9836 \\
7 & 13,982 & 22,060 & 12,124 & 11,958 \\
8 & 10,879 & 17,047 & 9461 & 9334 \\
9 & 1852 & 3317 & 1646 & 1588 \\
10 & 6568 & 10,312 & 5707 & 5630 \\
11 & 14,054 & 22,138 & 12,194 & 12,028 \\
\hline
\end{tabular}


Table 21. Internal heat gains per unit floor surface in the studied combinations.

\begin{tabular}{ccccc}
\hline \multirow{2}{*}{ Combination } & \multicolumn{3}{c}{ qINT Total Internal Heat Gain per Unit Floor Surface [W/m $\left.{ }^{2}\right]$} \\
\cline { 2 - 5 } & \multicolumn{3}{c}{ RFC } & \multicolumn{2}{c}{ Li-ion } \\
\cline { 2 - 5 } & Lunar Day & Lunar Night & Lunar Day & Lunar Night \\
\hline 1 & 84.68 & 132.91 & 73.59 & 72.60 \\
2 & 50.93 & 79.93 & 44.26 & 43.66 \\
3 & 85.03 & 133.29 & 73.93 & 72.94 \\
4 & 84.28 & 132.48 & 73.19 & 72.20 \\
5 & 84.86 & 133.10 & 73.76 & 72.77 \\
6 & 84.51 & 132.73 & 73.42 & 72.43 \\
7 & 102.96 & 162.45 & 89.28 & 88.05 \\
8 & 80.11 & 125.53 & 69.67 & 68.73 \\
9 & 13.64 & 24.43 & 12.12 & 11.69 \\
10 & 48.37 & 75.93 & 42.02 & 41.46 \\
11 & 103.49 & 163.02 & 89.80 & 88.57 \\
\hline
\end{tabular}

For Tables 20 and 21 an observation has been made that for a specified combination, the ratios of its IHG to the respective values in the reference combination are constant, no matter the ESS. These ratios are shown in Figure 7.

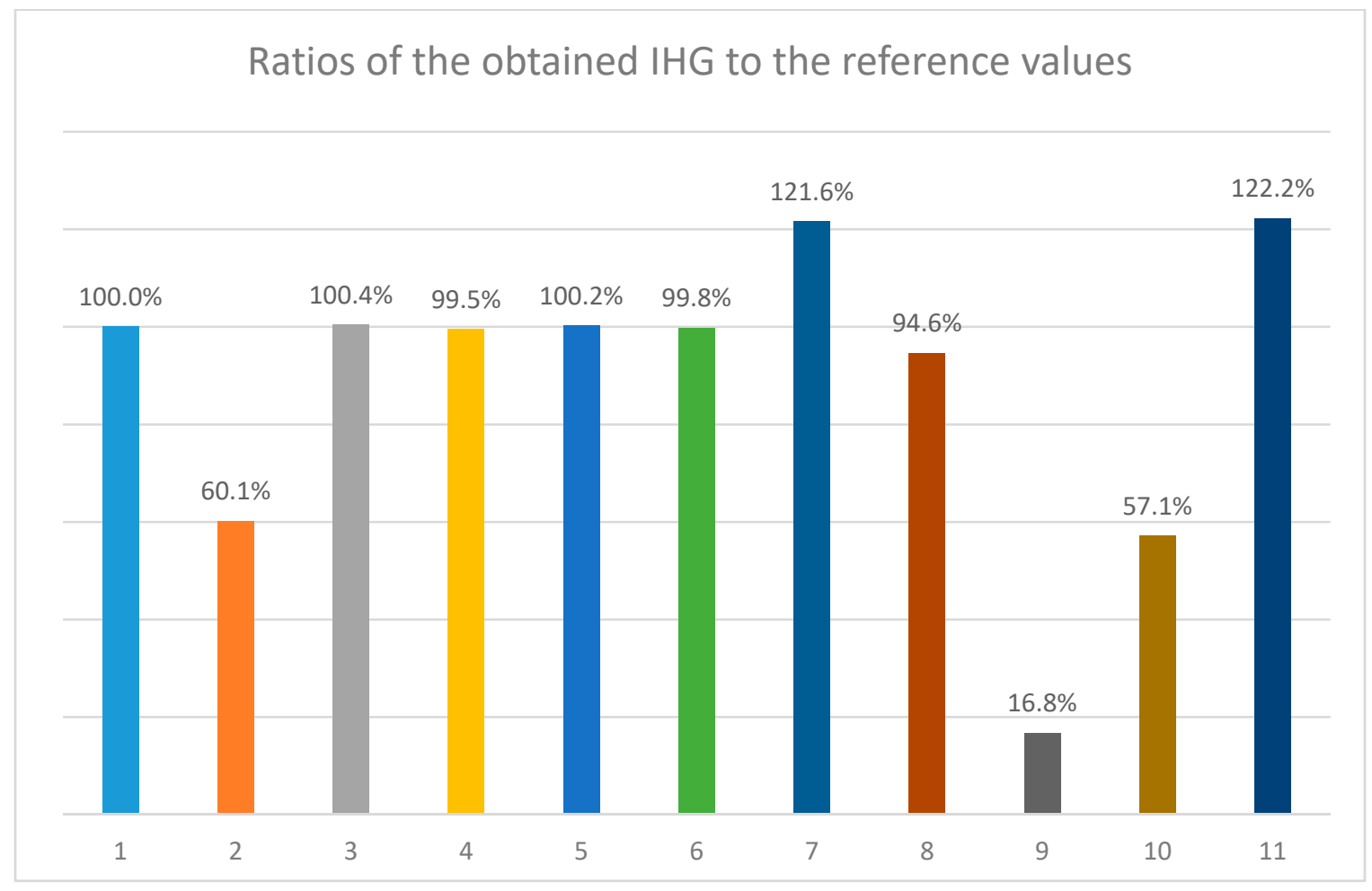

Figure 7. Ratios of the obtained internal heat gains (IHG) to the reference values.

One may observe, that combinations 3 to 6 exhibit negligibly lower differences from the reference value. This proves that within the assumed parameters range, the mean BSA of the crew and their physical activity profile is of little significance to the total IHG in the studied lunar base. Considering combinations 7 and 8 , it is to be stated, that predicted variations in electrical equipment use has a moderate influence on the total IHG being able to change the IHG within a range of $27 \%$ of its reference value. The number of base inhabitants has the most profound impact on the internal heat gain of the studied object. In order to depict this dependency as clearly as possible, we performed additional calculations for four and five-personnel crews. The results are shown in Figure 8. 


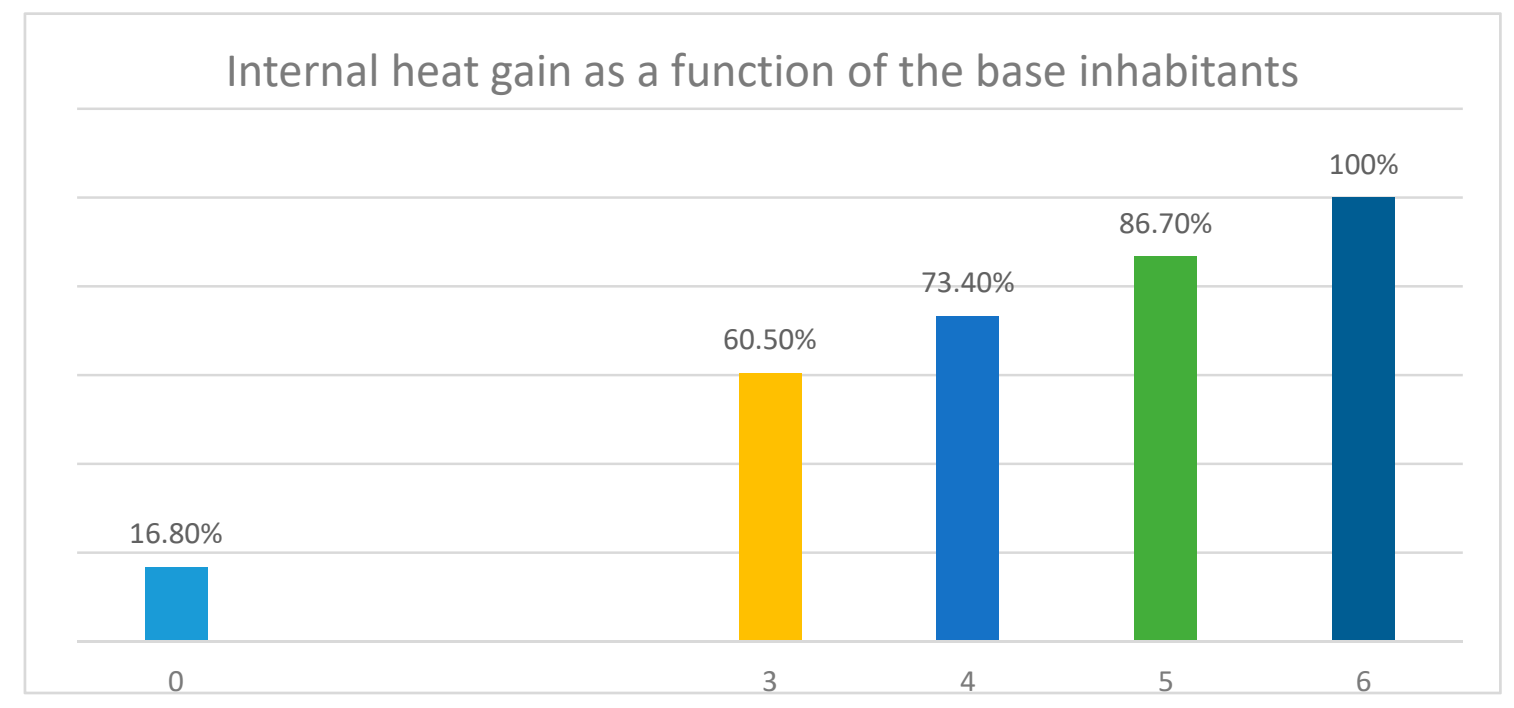

Figure 8. Dependence of the total IHG on the number of base inhabitants.

To explain this strong influence of the number of lunar base inhabitants on its total IHG, one should compare the detailed results of our analysis presented in the Table 19, combinations nos. 1 and 2 . The absolute difference in occupational heat load generated by 6 and 3 people is noticeable, but relatively low in comparison to the differences in the remaining heat loads. Most significant here is the fact, that accommodating a human in a lunar base implies an increased power demand on the environmental control and life support system, which in turn, intensifies waste heat generation by the energy storage system. This is why the resulting relative change of IHG between a full crew and half a crew is as high as $40 \%$.

The last two combinations (10 and 11) constitute superpositions of extreme values of the previously discussed parameters. In comparing these two, one may conclude that within the assumed range of parameters, the total IHG of the inhabited lunar base may vary up to $65 \%$ of the reference value.

The last, but definitely not least, is the configuration no.9, that represents a temporarily uninhabited base. In that configuration the total IHG of the base is reduced to just $16.8 \%$ of the nominal value and may be as low as $11.69 \mathrm{~W} / \mathrm{m}^{2}$. For both RFC and Li-ion based energy storage, the IHG of the uninhabited base were too low to compensate for lunar night-time heat losses. In this single case, the base TCS must have to switch into its heating mode, in order to maintain the required interior temperature.

It is to be noted, that the lunar base operation strategies assumed for this parametric study will, in fact, depend on many variables; such as established safety policies and risk management, surveillance, automation and remote control capabilities, on applied technical solutions and hardware specifications. As these factors are impossible to be precisely predicted at this moment, it was found unnecessary to perform a more detailed statistical analysis, while its basic assumptions themselves may carry such uncertainties. The validity of these assumptions is unlikely to be assessed until an actual lunar base becomes operational. As soon as actual case study data are available, that parametric study may become an interesting subject of a separate analysis.

Flexible TCS that may operate at a wide range of capacity, including an ability to provide heat for an uninhabited base during lunar nights.

\section{Conclusions}

Internal heat gain will be the most important component of the thermal balance of lunar facilities, even at the equatorial regions of the Moon. Lunar environmental heat loads were found to be relatively low in comparison with the internal heat gain produced by occupancy, electric devices and the energy storage system. The calculated values of the lunar base internal heat gain greatly exceed the values observed in terrestrial residential and office buildings, but are comparable with the internal heat gains 
of industrial facilities. They are, however, much lower than the $250 \mathrm{~W} / \mathrm{m}^{2}$ used in one of the previous studies. The orbital space station internal heat loads model must therefore be considered unsuitable for lunar buildings, and the energy consumption of outdated equipment must be periodically updated by performing similar studies. Most of the heat load produced in the lunar base by electric devices comes from various life support systems, as well as from the interplanetary communication system. As a result of living in partial gravity, man's sensible body heat production in lunar conditions is noticeably lower compared to terrestrial conditions. On the other hand, total occupational heat loads are significantly contributed by latent heat loads, what is rarely the case in buildings on Earth. Round trip energy efficiency of the energy storage system being used has a considerable impact on the internal heat gain in a lunar base. The values of energy efficiency of regenerative and discharge cycles should be similar, in order to avoid significant variations between lunar day and night internal heat gains. These parameters argue in favour of Li-ion batteries, which may be an optimal choice for a lunar base energy storage system. On the contrary, regenerative fuel cells were considered inconvenient for energy storage in lunar bases due to their high waste heat production resulting from the relatively low energy efficiency of their discharge cycle. The parametric study was conducted, in order to evaluate the influence of selected parameters on the total internal heat gain of the base. Within assumed parameters range, the IHG varied between 41.5 and 163. The number of inhabitants turned out to be the most significant factor that influences the total IHG of the lunar base. When the base is uninhabited, its thermal control system must compensate for significantly reduced IHG, and switch from cooling to heating mode in order to keep the base temperature at the assumed level. For a future study, a Finite Elements model will be developed for a more reliable determination of the external heat loads of a lunar base at a wide range of selenographic latitudes. To ultimately answer the problem of the most optimal energy storage system for a solar powered lunar base, additional studies are necessary, concerning the total power demand of a lunar base, proper photovoltaic power plant design, and total system mass. The administrator of LUNARES may consider this research as a baseline for the future development of the habitat. Information contained in this paper may contribute to all future analogue missions by increasing the fidelity of the research conducted onboard these objects.

Author Contributions: Conceptualisation, M.K.; Methodology, M.K.; Formal Analysis, M.K.; Investigation, M.K., A.S. and A.W.; Resources, M.K. and A.W.; Writing-Original Draft Preparation, M.K.; Writing-Review \& Editing, A.S. and A.W.; Supervision, A.S. and A.W.; Funding Acquisition, A.S. All authors have read and agreed to the published version of the manuscript.

Funding: This research received no external funding.

Acknowledgments: The authors would like to express their thanks to the Space Garden LTD., the owner and administrator of LUNARES for enabling this research to be conducted. Our gratitude also goes out to Artur Szalacha for formatting the draft.

Conflicts of Interest: The authors declare no conflict of interest.

\section{Nomenclature}

$\begin{array}{ll}\text { ISS } & \text { International Space Station } \\ \text { TCS } & \text { thermal control system } \\ \text { ESS } & \text { energy storage system } \\ \text { EVA } & \text { extra vehicular activity } \\ \text { PV } & \text { photovoltaic } \\ \text { RFC } & \text { regenerative fuel cell } \\ \text { Li-ion } & \text { lithium-ion } \\ \text { BSA } & \text { body surface area }\left(\mathrm{m}^{2}\right) \\ \text { MET } & \text { metabolic equivalent of task } \\ \text { PA } & \text { physical activities } \\ \text { TPR } & \text { total performance ratio } \\ \text { IHG } & \text { internal heat gain }\end{array}$




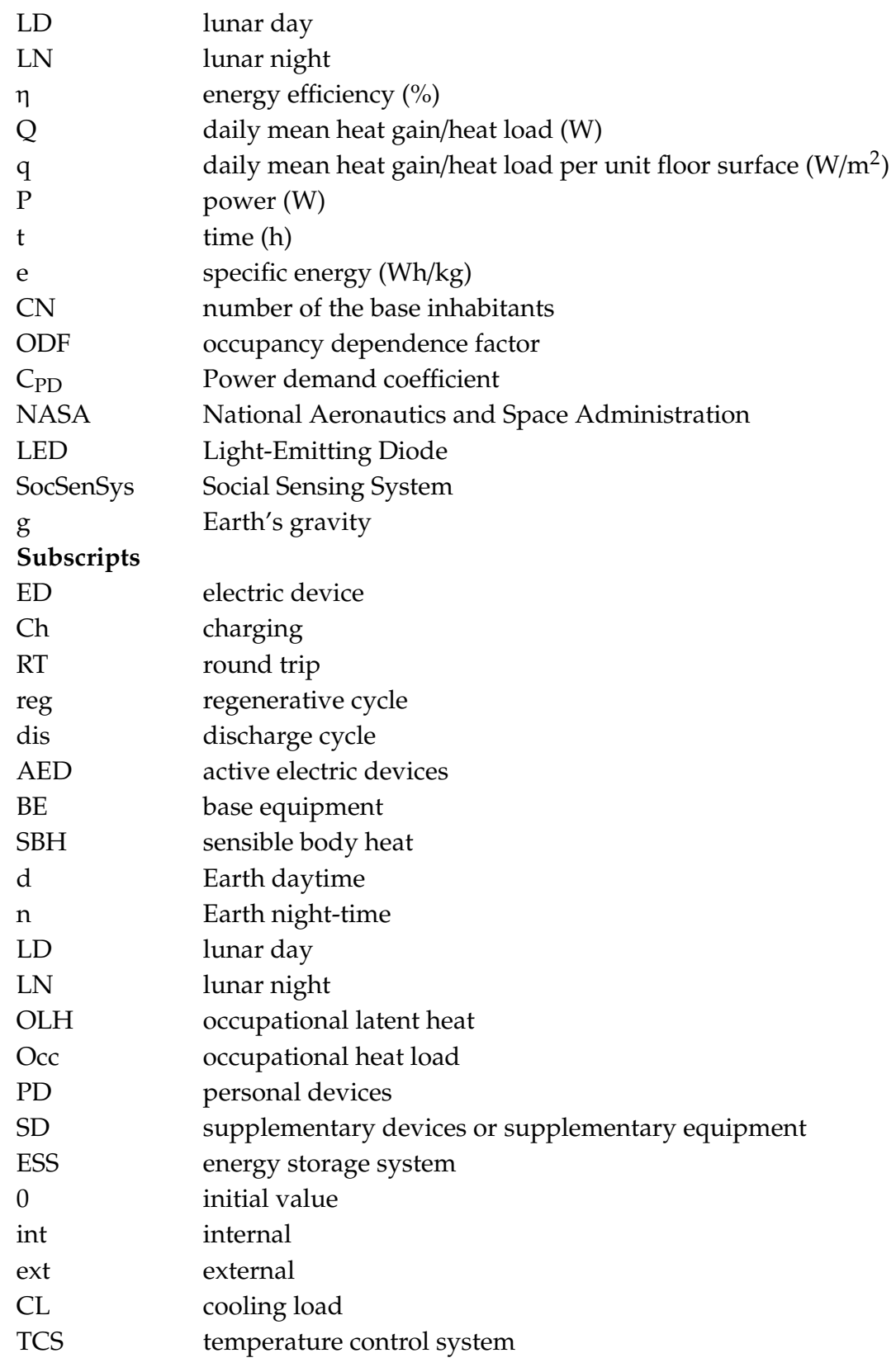

\section{References}

1. Publications HI-SEAS. Available online: http://hi-seas.org/wp-content/uploads/2016/05/HISEASMediaKit_ 01APR2016.pdf (accessed on 4 June 2020).

2. FMARS-Flashline Mars Arctic Research Station. Available online: http://fmars.marssociety.org/ (accessed on 4 June 2020).

3. Mars Desert Research Station. Available online: https://mdrs.marssociety.org/ (accessed on 4 June 2020).

4. Heinicke, C.; Orzechowski, L.; Abdullah, R.; von Einem, M.; Arnhof, M. Updated design concepts of the Moon and Mars Base Analog (MaMBA). In Proceedings of the European Planetary Science Congress 2018, Berlin, Germany, 16-21 September 2018. id. EPSC2018-599.

5. Elsarrag, E.; Alhorr, Y. Modelling the thermal energy demand of a Passive-House in the Gulf Region: The impact of thermal insulation. Int. J. Sustain. Built Environ. 2012, 1, 1-15. [CrossRef]

6. Coşkun, T.; Turhan, C.; Arsan, Z.D.; Akkurt, G.G. The importance of internal heat gains for building cooling design. J. Therm. Eng. 2017, 3, 1060-1064. [CrossRef] 
7. Internal Heat Gain-An Overview ScienceDirect Topics. Available online: https://www.sciencedirect.com/ topics/engineering/internal-heat-gain (accessed on 19 January 2020).

8. Monstvilas, E.; Banionis, K.; Stankevičius, V.; Karbauskaite, J.; Bliūdžius, R. Heat gains in buildings_Limit conditions for calculating energy consumption. J. Civ. Eng. Manag. 2010, 16, 439-450. [CrossRef]

9. Baglivo, C.; Congedo, P.M.; Di Cataldo, M.; Coluccia, L.D.; D'Agostino, D. Envelope design optimization by thermal modelling of a building in a warm climate. Energies 2017, 10, 1808. [CrossRef]

10. Albatici, R.; Passerini, F.; Pfafferott, J. Energy performance of verandas in the building retrofit process. Energies 2016, 9, 365. [CrossRef]

11. Ahn, B.; Park, J.; Yoo, S.; Kim, J.; Leigh, S.; Jang, C. Savings in cooling energy with a thermal management system for led lighting in office buildings. Energies 2015, 8, 6658-6671. [CrossRef]

12. Park, S.; Kim, D.; Joe, G.; Ryu, S.; Yeo, M.; Kim, K. Establishing boundary conditions considering influence factors of the room equipped with a ceiling radiant cooling panel. Energies 2020, 13, 1684. [CrossRef]

13. Hanford, A.J. (Ed.) Advanced Life Support Baseline Values and Assumptions Document; NASA/CR-2004-208941; Lockheed Martin Space Operations: Houston, TX, USA, 2004.

14. Simonsen, L.C.; DeBarro, M.J.; Farmer, J.T.; Thomas, C.C. Conceptual design of a lunar base thermal control system. In Proceedings of the NASA Symposium on Lunar Bases and Space Activities in the 21st Century, Houston, TX, USA, 5-7 April 1988. LBS-88-225.

15. Swanson, T.D.; Radermacher, R.; Costello, F.A.; Moore, J.S.; Mengers, D.R. low-temperature thermal control for a lunar base. SAE Tech. Pap. 1990, 901242. [CrossRef]

16. Simonsen, L.J.; DeBarro, M.J.; Farmer, J.T. Conceptual Design of a Lunar Base Thermal Control System. Available online: https://ntrs.nasa.gov/archive/nasa/casi.ntrs.nasa.gov/19930004815.pdf (accessed on 10 December 2019).

17. Sridhar, K.R.; Gottmann, M. Lunar base thermal control systems using heat pumps. Acta Astronaut. 1996, 39, 381-394. [CrossRef]

18. Kaczmarzyk, M.; Gawroński, M.; Piatkowski, G. Global database of direct solar radiation at the Moon's surface for lunar engineering purposes. E3S Web Conf. 2018, 49, 00053. [CrossRef]

19. Kaczmarzyk, M.; Gawroński, M.; Piątkowski, G. Application of Finite Difference Method for determining lunar regolith diurnal temperature distribution. E3S Web Conf. 2018, 49, 00052. [CrossRef]

20. Evangelisti, L.; Guattari, C.; Gori, P.; Bianchi, F. Heat transfer study of external convective and radiative coefficients for building applications. Energy Build. 2017, 151, 429-438. [CrossRef]

21. Cole, R.J.; Sturrock, N.S. The convective heat exchange at the external surface of buildings. Build. Environ. 1977, 12, 207-214. [CrossRef]

22. Jayamaha, S.; Wijeysundera, N.; Chou, S. Measurement of the heat transfer coefficient for walls. Build. Environ. 1996, 31, 399-407. [CrossRef]

23. Bienhoff, B. The Future of Commercial Space Transportation. Available online: https://www.thespacereview. com/article/3776/1 (accessed on 4 June 2020).

24. Benaroya, H. Lunar habitats: A brief overview of issues and concepts. Reach 2017, 7-8, 14-33. [CrossRef]

25. Degtyarev, A.V.; Lobanov, L.M.; Kushnar'ov, A.P.; Baranov, I.Y.; Volkov, V.S.; Perepichay, A.O.; Korotenko, V.V.; Volkova, O.A.; Osinovyy, G.G.; Lysenko, Y.A.; et al. On possibilities for development of the common-sense concept of habitats beyond the Earth. Acta Astronaut. 2020, 170, 487-498. [CrossRef]

26. Landis, G.A.; Bailey, S.G. Photovoltaic power for a lunar base. Acta Astronaut. 1990, 22, 197-203. [CrossRef]

27. Fraser, S.D. Theory and applications of cooling systems in lunar surface exploration. In Moon Prospective Energy and Material Resources; Badescu, V., Ed.; Springer: New York, NY, USA, 2012; p. 405.

28. Kaczmarzyk, M.; Waśniowski, A. Internal heat loads in the LUNARES analogue planetary base-A case study. J. Civ. Eng. Environ. Archit. 2019, 3, 25-36. [CrossRef]

29. Grabowski, M.; Marschall, M.; Sirko, W.; Debski, M.; Ziombski, M.; Horban, P.; Acedanski, S.; Peczarski, M.; Batorski, D.; Iwanicki, K. An experimental platform for quantified crowd. In Proceedings of the 24th International Conference on Computer Communication and Networks, Las Vegas, NV, USA, 3-6 August 2015.

30. Rüb, I.; Matraszek, M.; Konorski, P.; Perycz, M. 30 Sensors to Mars: Toward distributed support systems for astronauts in space habitats. In Proceedings of the 39th IEEE International Conference on Distributed Computing Systems (ICDCS 2019), Dallas, TX, USA, 7-10 July 2019. 
31. Life Support Systems—Sustaining Humans Beyond Earth. Available online: https://www.nasa.gov/content/ life-support-systems (accessed on 23 January 2020).

32. Hemmati, H.; Biswas, A.; Djordjevic, I. Deep space optical communications: Future perspectives and applications. Proc. IEEE 2011, 99, 2020-2039. [CrossRef]

33. Ainsworth, B.; Haskell, W.; Herrmann, S.; Meckes, N.; Bassett, D.; Tudor-Locke, C.; Greer, J.; Vezina, J.; Whitt-Glover, M.; Leon, A. 2011 Compendium of physical activities: A Second update of codes and MET values. Med. Sci. Sports Exerc. 2011, 43, 1575-1581. [CrossRef]

34. Dubois, D.; Dubois, E.F. A formula to estimate the approximate surface area if height and weight be known. Arch. Intern. Med. 1916, 17, 863-871. [CrossRef]

35. Sanborn, W.G.; Wortz, E.C. Metabolic rates during lunar gravity simulation. Aerosp. Med. 1967, 38, 380-382. [PubMed]

36. Newman, D.J.; Alexander, H.L. Human locomotion and workload for simulated lunar and Martian environments. Acta Astronaut. 1993, 29, 613-620. [CrossRef]

37. Goldberg, J.H.; Alred, J.W. Prediction of physical workload in reduced gravity. Aviat. Space Environ. Med. 1988, 12, 1150-1157.

38. Wortz, E.C. Work in reduced-gravity environments. Hum. Factors 1969, 11, 433-439. [CrossRef] [PubMed]

39. Robertson, W.; Wortz, E. The effects of lunar gravity on metabolic rates. In NASA Contractor Report; NASA CR-1102; NASA: Washington, DC, USA, 1968.

40. Norcross, J.; Lee, L.; Clowers, K.; Morency, R.; Desantis, L.; De Witt, J.; Jones, J.; Vos, J.; Gernhardt, M. Feasibility of performing a suited 10-km ambulation on the Moon-Final report of the EVA Walkback Test (EWT). In NASA Technical Publication 2009; NASA: Washington, DC, USA, 2009; TP-2009-214796.

41. Richter, C.; Braunstein, B.; Winnard, A.; Nasser, M.; Weber, T. Human biomechanical and cardiopulmonary responses to partial gravity-A systematic review. Front Physiol. 2017, 8, 583. [CrossRef] [PubMed]

42. Garcia, C.P.; Chang, B.-J.; Johnson, D.W.; Bents, D.J.; Scullin, V.J.; Jakupca, I.J. Round trip energy efficiency of NASA Glenn regenerative fuel cell system. In NASA Technical Memorandum 2006; NASA: Washington, DC, USA, 2006; TM-2006-214054.

43. Valøena, L.O.; Shoesmithb, M.I. The Effect of Phev and Hev Duty Cycles on Battery and Battery Pack Performance. Available online: http://umanitoba.ca/outreach/conferences/phev2007/PHEV2007/proceedings/ PluginHwy_PHEV2007_PaperReviewed_Valoen.pdf (accessed on 20 January 2020).

44. Lithium-Ion Batteries-An Overview. ScienceDirect. Available online: https://www.sciencedirect.com/topics/ engineering/lithium-ion-battery (accessed on 22 January 2020).

45. Patsios, C.; Wu, B.; Chatzinikolaou, E.; Rogers, D.; Wade, N.; Brandon, N.; Taylor, P. An integrated approach for the analysis and control of grid connected energy storage systems. J. Energy Storage 2016, 5, 48-61. [CrossRef]

46. Active Thermal Control System (ATCS) Overview-NASA. Available online: https://www.nasa.gov/pdf/ 473486main_iss_atcs_overview.pdf (accessed on 12 January 2020).

47. Neto, A.; Fiorelli, F. Comparison between detailed model simulation and artificial neural network for forecasting building energy consumption. Energy Build. 2008, 40, 2169-2176. [CrossRef]

48. Kim, H.; Park, K.; Kim, H.Y.; Song, Y. Study on variation of internal heat gain in office buildings by chronology. Energies 2018, 11, 1013. [CrossRef]

49. Goodfellow, H.D.; Tahti, E. Industrial Ventilation Design Guidebook; Elsevier: Amsterdam, The Netherlands, 2001; p. 1076. Available online: https://books.google.com/books/about/Industrial_Ventilation_Design_ Guidebook.html?id=t9O8xvY_XoUC (accessed on 14 January 2020).

50. Grigore, R.; Dima, C. Research on the influence of internal heat gains on energy performance evaluation of industrial buildings. In Proceedings of Plumee 2015; Alma Mater Publishing House: Bacau, Romania, 2015; Available online: http://pubs.ub.ro/dwnl.php?id=PLUMEE201501V05S01A0009 (accessed on 24 January 2020).

51. Shiel, W.C., Jr. Medical Definition of Body Surface Area-MedicineNet. Available online: https://www. medicinenet.com/script/main/art.asp?articlekey=39851 (accessed on 1 June 2020).

52. Statista-Chart: Number of Female NASA Astronauts Rises. Available online: https://www.statista.com/ chart/17487/number-of-female-nasa-astronauts/ (accessed on 2 June 2020). 
53. Mark, S.; Iscott, G.B.; Donoviel, D.B.; Leveton, L.B.; Mahoney, E.; Charles, J.B.; Siegel, B. The Impact of Sex and Gender on Adaptation to Space: Executive Summary. Available online: https://www.ncbi.nlm.nih.gov/ pmc/articles/PMC4236030/ (accessed on 2 June 2020).

54. Physical Activity in Space-Canadian Space Agency. Available online: https://www.asc-csa.gc.ca/eng/ astronauts/living-in-space/physical-activity-in-space.asp (accessed on 2 June 2020).

(C) 2020 by the authors. Licensee MDPI, Basel, Switzerland. This article is an open access article distributed under the terms and conditions of the Creative Commons Attribution (CC BY) license (http://creativecommons.org/licenses/by/4.0/). 